OPEN ACCESS

Edited by:

Nan Zhu,

Dalian University of Technology, China

Reviewed by:

Arnab Halder,

Linköping University, Sweden

Xintai Wang,

University of Cambridge,

United Kingdom

Minwei Zhang,

Xinjiang University, China

${ }^{*}$ Correspondence:

Christophe Egles

christophe.egles@utc.fr

Erwann Guénin

erwann.guenin@utc.Fr

Specialty section: This article was submitted to

Polymer Chemistry a section of the journal

Frontiers in Chemistry

Received: 09 September 2020 Accepted: 09 November 2020

Published: 01 December 2020

Citation:

Belda Marín C, Fitzpatrick V, Kaplan DL, Landoulsi J, Guénin E and

Egles C (2020) Silk Polymers and

Nanoparticles: A Powerful

Combination for the Design of

Versatile Biomaterials.

Front. Chem. 8:604398.

doi: $10.3389 /$ fchem.2020.604398

\section{Silk Polymers and Nanoparticles: A Powerful Combination for the Design of Versatile Biomaterials}

\author{
Cristina Belda Marín ${ }^{1,2}$, Vincent Fitzpatrick ${ }^{3}$, David L. Kaplan ${ }^{3}$, Jessem Landoulsi ${ }^{2}$, \\ Erwann Guénin ${ }^{1 *}$ and Christophe Egles ${ }^{4 *}$ \\ ${ }^{1}$ Laboratory of Integrated Transformations of Renewable Matter (TIMR), Université de Technologie de Compiègne, ESCOM, \\ Compiègne, France, ${ }^{2}$ Laboratoire de réactivité de surface (UMR CNRS 7197), Sorbonne Université, Paris, France, \\ ${ }^{3}$ Department of Biomedical Engineering, Tufts University, Medford, MA, United States, ${ }^{4}$ Biomechanics and Bioengineering, \\ CNRS, Université de Technologie de Compiègne, Compiègne, France
}

Silk fibroin (SF) is a natural protein largely used in the textile industry but also in biomedicine, catalysis, and other materials applications. SF is biocompatible, biodegradable, and possesses high tensile strength. Moreover, it is a versatile compound that can be formed into different materials at the macro, micro- and nano-scales, such as nanofibers, nanoparticles, hydrogels, microspheres, and other formats. Silk can be further integrated into emerging and promising additive manufacturing techniques like bioprinting, stereolithography or digital light processing 3D printing. As such, the development of methodologies for the functionalization of silk materials provide added value. Inorganic nanoparticles (INPs) have interesting and unexpected properties differing from bulk materials. These properties include better catalysis efficiency (better surface/volume ratio and consequently decreased quantify of catalyst), antibacterial activity, fluorescence properties, and UV-radiation protection or superparamagnetic behavior depending on the metal used. Given the promising results and performance of INPs, their use in many different procedures has been growing. Therefore, combining the useful properties of silk fibroin materials with those from INPs is increasingly relevant in many applications. Two main methodologies have been used in the literature to form silk-based bionanocomposites: in situ synthesis of INPs in silk materials, or the addition of preformed INPs to silk materials. This work presents an overview of current silk nanocomposites developed by these two main methodologies. An evaluation of overall INP characteristics and their distribution within the material is presented for each approach. Finally, an outlook is provided about the potential applications of these resultant nanocomposite materials.

Keywords: natural polymers, silk, nanoparticles, bioactive biomaterials, regenerative medicine

\section{INTRODUCTION}

Silk is a natural polymer originating from various insect and spider species. It is composed of two different proteins, sericin and fibroin, among which fibroin is an FDA-approved material for some medical devices. Due to the remarkable mechanical properties, biocompatibility and biodegradability, fibroin has been shaped into various scaffolds, including sponges, electrospun 
mats, microspheres, hydrogels, aerogels, foams, and 3D printed structures. These silk-based scaffolds are particularly investigated in various tissue engineering applications, including for bone, nerve, skin, cartilage or corneal regeneration, but also as vehicles for drug delivery. These materials are also studied in other scientific areas such as for pollution control, electronics, optics, and material science in general.

Moreover, silk fibroin can be blended with different additives to form scaffolds with new properties. Among these, nanocomposites which comprise silk polymers and nanoparticles (NPs) have gained increasing interest due to the outstanding properties of the NPs, which differ in their properties from bulk materials. Accordingly, the development of silkNPs nanocomposites has triggered growing interest for both academic and industrial research. Combining the assets of silk fibroin materials with those from NPs is appealing to obtain new properties that are unattainable by "classical" composites consisting of the same bulk materials.

In this review, we present an overview of current nanocomposites constituted of silk fibroin and NPs with particular attention to inorganic NPs (INPs), typically metals, oxides, and bioceramics. First, we present current knowledge on silk-based scaffolds and their main applications. We then describe the principal INPs (synthesis, properties) used to produce these composites. Finally, we provide an outlook of the potential applications of the resultant nanocomposite materials and guidelines for tuning their properties and functions.

\section{SILK}

\section{Silk Structure and Extraction}

Silks are protein biopolymers produced by many members of the arthropod family such as spiders, silkworms, flies, and silverfish. Each arthropod produces silk components with a different amino acid composition, resulting in different structural properties (Xiong et al., 2018). Mechanical properties are different, with some spider silks being stronger than silkworms silk. In addition, silk properties are influenced by other parameters, such as the environment and arthropod nutrition, giving rise to different silk types produced by the same species (Koh et al., 2015). Among existing silks, mulberry worm silks are the most commonly used for textiles and biomedical applications. Although some spider silks have greater tensile strength, toughness and extensibility, the cannibalistic nature of spiders makes the development of industrial production of spider silks with high yield impossible. Bombyx mori silkworms, on the other hand, were domesticated for industrial silk production centuries ago. As such, silkworm silk is almost exclusively used for medical and related applications, and for this reason only B. mori silk is considered in the following sections.

\section{Bombyx mori Silk Structure}

Silk fibers consist of two main proteins form B. mori silk: fibroin and sericin. Silk fibers are composed of fibroin microfibrils assembled into filaments. Silk fibers consist of two fibroin filaments each produced by one of the worm's salivary glands during spinning. Both filaments are then covered by sericin, an adhesive and hydrophilic protein to form the structural unit (Poza et al., 2002).

Fibroin is an hydrophobic protein formed by two chains: a light chain (L-chain, $\sim 26 \mathrm{kDa}$ ); and a heavy chain (H-chain, $\sim 390 \mathrm{kDa}$ ). The two fibroin chains are covalently linked by a disulfide bond between two cysteines, forming a H-L complex. The formation of this complex is essential for the secretion of silk fibroin from producing cells to the glands. The primary structure of silk fibroin (SF) is formed by highly repetitive sequences composed mainly of glycine $(43 \%)$, alanine $(30 \%)$ and serine $(12 \%)$. Other amino acids such as tyrosine (5\%), valine (2\%), and tryptophan are present in smaller proportions (Koh et al., 2015). The primary structure of the H-chain contains 12 repetitive hydrophobic domains interspersed with 11 nonrepetitive hydrophilic regions. Three different polymorphs of SF (silk I, II, and III) have been reported; Silk I adopts a coiled structure and is found in the silk stored in the arthropods' glands. This conformation is also found in regenerated aqueous dispersions in vitro. Silk II corresponds to the antiparallel $\beta$ sheet crystal structure obtained once silk has been spun. In the laboratory, this polymorph results from the exposure of silk I to mechanical/physical and chemical treatments, such as stirring, heating, exposure to methanol or water annealing procedures. The formation of the $\beta$-sheet structure is possible due to the rearrangement of the repetitive regions that form the $\mathrm{H}$-chain of SF, and the intra and intermolecular interactions by hydrogen bonding, van Der Waals forces and hydrophobic interactions. $\mathrm{X}$-ray diffraction (XRD) analysis of the crystallinity regions of SF found an antiparallel $\beta$-sheet structure. The non-repetitive domains adopt a coiled conformation. Silk II excludes water from the structure, giving strength to the protein filament and making it insoluble in water and other solvents like mild acids or bases. The third polymorph, silk III, adopts a helical structure at air-water interfaces (Vepari and Kaplan, 2007).

\section{Regenerated Silk Fibroin Extraction}

Some studies have shown that sericin may induce an immunogenic response in the human body while SF has been approved by the FDA for medical use in the US (Zhang et al., 2017). Sericin is therefore removed from silk for biomedical applications (Rockwood et al., 2011). B. mori silk cocoons are processed to obtain a regenerated SF solution. This procedure differs from that used by the textile industry as the final objective is not to obtain silk fibers but a SF solution. The goal is to bring silk (polymorphs II and III) to the initial state found in the glands of the worm (silk I) before being spun. This transformation can be achieved by denaturing SF proteins, which result in protein solution (Rockwood et al., 2011). Briefly, silk cocoons are boiled in a sodium carbonate $\left(\mathrm{Na}_{2} \mathrm{CO}_{3}\right)$ solution to remove the sericin (soluble in hot water) that glues together the SF filaments. Boiling time is a crucial parameter influencing the properties of SF in solution. Longer times will disrupt SF chains to lower molecular weight. Boiling silk cocoons for $30 \mathrm{~min}$ will result in $\sim 100 \mathrm{kDa}$ fibroin proteins (Rockwood et al., 2011). Once boiled, the resulting entangled cotton-like fibers are abundantly rinsed in distilled water (to remove any remaining sericin) to obtain the 
SF dispersion prior to solubilization in various, albeit limited, salt and related systems.

Different solvents can be used for complete dissolution of the $\mathrm{SF}$, the most common being lithium bromide ( $\mathrm{LiBr}$ ) (Xiong et al., 2018). Briefly, a LiBr solution is mixed with the extracted and dried SF fibers and heated for a specific time (Rockwood et al., 2011). LiBr allows the destabilization of hydrogen bonds found in silk II polymorph; allowing the shift to the silk I structure (Xiong et al., 2018). LiBr is a chemical hazard that can cause skin and eye irritation, encouraging the search for alternative solutions. Another solvent used to dissolve silk fibroin fibers is a ternary system composed of calcium chloride, ethanol and water (Song et al., 2017). Ionic liquids have also been used to dissolve silk, such as 1-butyl-3-methylimidazolium chloride (BMIM Cl), 1-butyl2,3-dimethylimidazolium chloride (DMBIM Cl) and 1-ethyl-3methylimidazolium chloride (EMIM Cl) (Phillips et al., 2004). The solution obtained in the above process must be dialyzed with distilled water to remove the salts. Finally the protein solution is centrifuged twice to remove any solid impurities (Rockwood et al., 2011). The resultant solution is around 6$8 \% \mathrm{w} / \mathrm{v}$ SF and can be further concentrated up to around $30 \%$. Regenerated SF dispersion should be handled with care, as many procedures such as heating, stirring or $\mathrm{pH}$ variations will induce protein rearrangement, forming $\beta$-sheet structures and resulting in the gelation of the solution. Because of this, regenerated SF dispersion should be stored at $4^{\circ} \mathrm{C}$ and for no longer than 1 month.

Unlimited storage can be achieved by lyophilizing the SF solution. Lyophilized product can be redissolved in water, formic acid or 1,1,1,3,3,3-hexafluoro-2-propanol (HFIP) (Rockwood et al., 2011) at the desired concentration.

\section{Silk-Based Materials}

Silk is traditionally known for its wide use in the textile industry given its lightweight, soft touch, and luster. The $\beta$-sheet structure found in silk II polymorph is responsible for silk's mechanical properties, which are well-beyond most known biopolymers. Because of its unique properties and its versatility, a wide range of materials with various properties can be obtained from a SF dispersion or its lyophilized powder. Figure 1 shows some of the multiple materials that can be obtained from silk fibroin. Most techniques used to construct SF materials are based on the controlled formation of $\beta$ sheet structures. Which enables tailoring mechanical properties, rates of biodegradation, and the degree of solvent dissolution of the silk.

\section{Silk Fibroin Sponges}

Silk fibroin sponges are 3D porous materials for which pore size and interconnectivity can be controlled depending on the production method. Silk fibroin sponges can be produced by mixing the silk solution with a porogen (e.g., salt or sugar crystals, polymer or mineral beads) and subsequently inducing silk gelation. Many different procedures have been described, such as the use of sodium chloride (salt leaching), freeze casting (Cai et al., 2017a), or HFIP solvent (Rockwood et al., 2011). Silk fibroin sponges can be used as scaffolds for bone tissue regeneration due to their macroporous structure that can be tailored to promote the enhanced formation of new and vascularized bone tissue (Karageorgiou and Kaplan, 2005). Several in vitro and in vivo studies have demonstrated the potential of cellularized scaffolds or acellular silk materials for bone regeneration (Bhattacharjee et al., 2017).

\section{Electrospun Mats}

Electrospinning is a simple technique that consists of using of an electric field to spin a polymer solution into a non-woven mat composed of nanometer diameter fibers. During electrospinning, the polymer solution is placed in a syringe with a conductive needle connected to a high voltage electric field $(5-40 \mathrm{kV})$. A grounded conductive collector is placed at a distance in front of the needle. While the polymer solution is extruded through the needle, the high voltage electric field induces its stretching, allowing the formation of nanofibers. During the process, the solvent evaporates at rates dependent on its intrinsic properties and experimental conditions, and the fibers are deposited on the collector due to the voltage difference (Rockwood et al., 2011). The nature of the collector used impacts the fiber alignment. If a flat static collector is used, fibers are randomly deposited. A rotating mandrel used as a collector results in alignment of the deposited fibers (Rockwood et al., 2011), useful for some applications, such as direction control of growth in neural regeneration (Belanger et al., 2018).

The fiber diameter obtained by electrospinning can be modulated by adjusting extrinsic parameters: polymer concentration, solvent, polymer extrusion flow rate, needle-tocollector distance, and the applied voltage. The electrospinning procedure may also be sensitive to intrinsic factors such as the molecular weight of the silk. Silk fibroin electrospinning is also dependent on humidity and temperature. A non-controlled variation in one of these parameters will alter the characteristics of final material. Electrospun mats can be used in the field of wound dressings, textiles, wearable electrodes, nerve guides, and other systems (Yukseloglu et al., 2015).

\section{Microspheres}

Silk microspheres can be produced by several methods; encapsulation in fatty acids creating an emulsion, phase separation of silk from another polymer such as poly(vinyl alcohol) (PVA) (Rockwood et al., 2011), or adding potassium phosphate to the aqueous silk solution (Lammel et al., 2010). Silk has been extensively used for drug delivery, both as a vehicle and due to its stabilizing effect on bioactive molecules and enzymes (Li A. B. et al., 2015). Silk microspheres are of interest as an encapsulating material in this field, because modulating their degradation rate results in controlled release of the contents (Lan et al., 2014; Li H. et al., 2017).

\section{Hydrogels}

Hydrogels are of interest due to their mechanical properties akin to soft tissues in the body. In addition, their capacity to swell and retain a high liquid volume renders them interesting for depollution applications, such as in environmental hazard removal (Hou et al., 2018). Hydrogels can be used to replace 


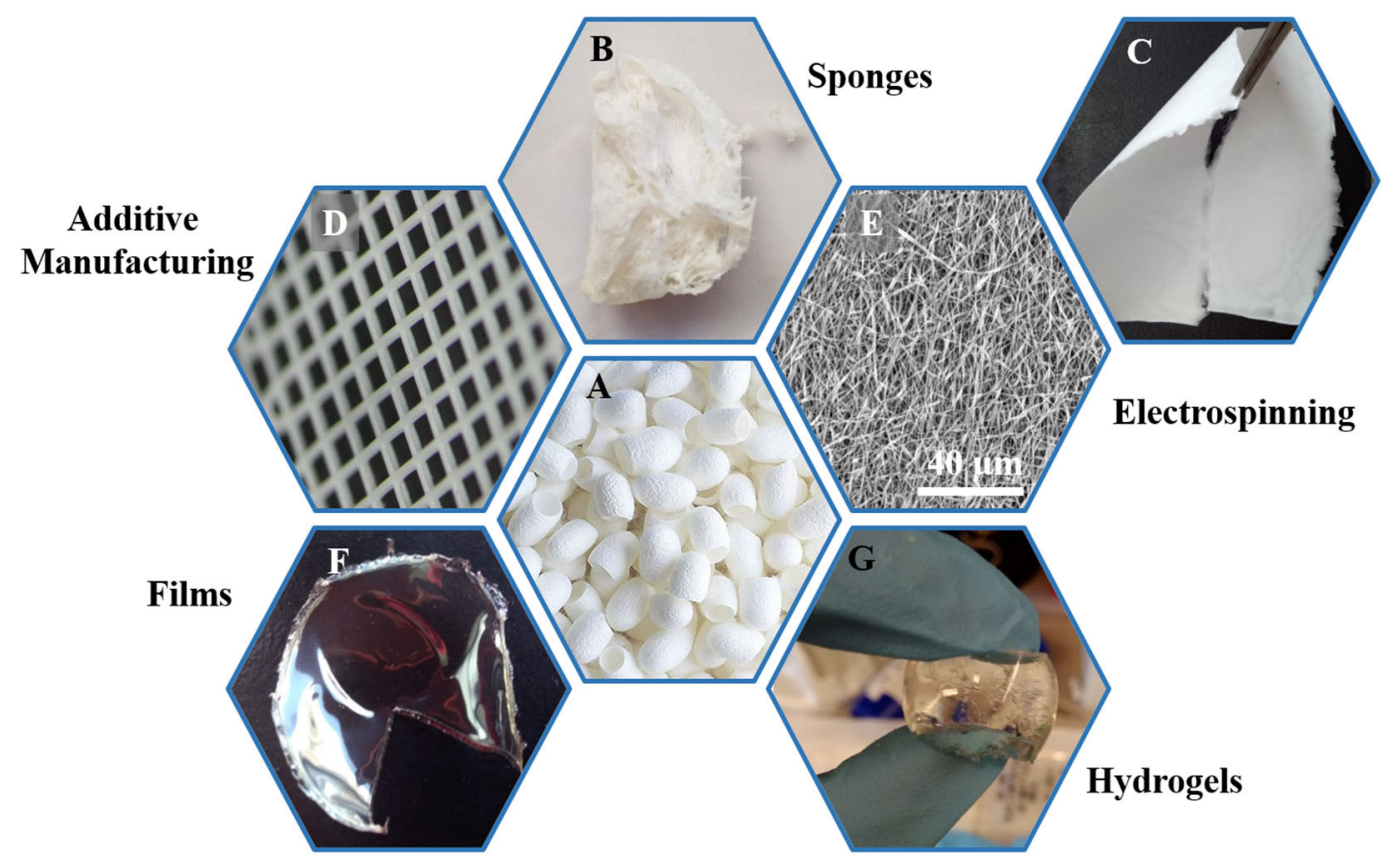

Aerogels

FIGURE 1 | Overview of the various biomaterials obtained from of silk fibroin extracted from silk cocoons (A). Silk cocoons (A), sponges (B), macroscopic and microscopic images of electrospun mats (C,E), 3D printed structures (D), films (F), hydrogels (G), and aerogels (H).

damaged soft tissues such as cartilage, the intervertebral disc, cornea and skin, among others. SF hydrogels can be found in applications such as drug delivery (Niu et al., 2019), tissue engineering (Vidal et al., 2019), regenerative medicine (Fernández-García et al., 2016; Frauchiger et al., 2017; Li et al., 2020), and catalysis (Luo and Shao, 2017).

The formation of hydrogels consists of the rearrangement of SF molecules to form crystalline structures as physical crosslinks. For this purpose, many protocols have been described in the literature to control the characteristics of the gels. Physical, photochemical, and chemical-induced gelation methods have been reported. "Physical gelation" occurs through the formation of physical interactions, including electrostatic (coulombic) and van der Waals. Physical gelation protocols include solution sonication (Fernández-García et al., 2016), vortexing, the application of an electrical current or a $\mathrm{pH}$ decrease below the pI (Rockwood et al., 2011). "Chemical gelation" consists of the formation of new covalent bonds (crosslinks) via enzymes, chemical catalysts, or other chemical species. Protocols mostly involve the use of enzymes, such as oxidases, phosphatases, transglutaminases, or peroxidases (Nezhad-Mokhtari et al., 2019).

\section{Enzyme-assisted crosslinking}

Enzymatic crosslinking offers in situ crosslinking and interactions with the surrounding extracellular matrix (NezhadMokhtari et al., 2019). Moreover, enzymatic-catalyzed reactions are specific and their rates are tunable, thus allowing a good control over the reaction products. Although many enzymes have been used to form such hydrogels, horseradish peroxidase (HRP) is the most extensively used.

\section{HRP-crosslinked hydrogels}

Commercially available horseradish peroxidase is extracted from the roots of Armoracia rusticana. In the plant, many different isoenzymes have been identified, although the most common one is HRP C. HRP is an oxidoreductase that catalyzes the conjugation of phenol and aniline derivatives in the presence of hydrogen peroxide $\left(\mathrm{H}_{2} \mathrm{O}_{2}\right)$. In proteins, the action of HRP results in the formation of dityrosine bonds between the phenol groups present on tyrosine. The incorporation of tyramine in enables crosslinking by HRP (Bang et al., 2017; Bi et al., 2019). The use of this enzyme to crosslink peptides, polysaccharides and polymers has been extensively described in the literature (Hoang Thi et al., 2019; van Loo et al., 2020). In particular, HRPcrosslinked SF hydrogels have been described (Partlow et al., 2014), including the structure, crosslinking kinetics, rheological, and mechanical properties, as well as the cytotoxicity and biocompatibility of the hydrogels formed in the process. The properties of these SF hydrogels were tunable depending on several parameters, including silk fibroin molecular weight and concentration. In addition, the all-aqueous procedure, together with its biocompatibility and in vivo tolerance, makes this hydrogel a good candidate for biomedical applications and the 
encapsulation of biological factors (growth factors, hormones, cytokines), while preserving their activity.

\section{Aerogels}

Aerogels are open porous materials of very low density that derive from replacing the liquid component of a gel by a gas. Silk aerogels are generally produced by freeze drying a silk solution or hydrogel. Similar to sponge materials, a 3D porous scaffold is obtained (Xiong et al., 2018) and pore size and distribution can be tuned by controlling the rate of freezing. One example of the process is an ice templating technique that consists in controlling ice crystal growth in the silk sample to obtain a desired structure. Microchannel containing silk scaffolds can be obtained by this technique (Qian and Zhang, 2011; Xiong et al., 2018). Aerogels have been used as fire retardant materials, thermal insulators (Maleki and Huesing, 2019), pollution control materials, and as biomaterials (Mandal and Kundu, 2009).

\section{D Printed Structures}

The development of 3D printing technologies has made it possible to print polymer dispersions, including silk structures. This approach controls the shape and dimensions of the structures (Mu et al., 2020). Many silk-containing bioinks or 3D printing techniques are being developed with silk inks. Some approaches have focused on the properties of silk to obtain a construct, for example, by printing in a saline bath to induce hierarchical assembly of the silk proteins ( $\mathrm{Mu}$ et al., 2020), or using freeform printing in a bath of synthetic nanoclay and polyethylene glycol (PEG) for a one-step process of printing and in situ physical gelation (Rodriguez et al., 2018). Other strategies have focused on mixing SF with other polymers and thickening agents, such as PEG (Zheng et al., 2018), polyols (Jose et al., 2015) or the polysaccharide Konjac glucomannan (Sommer et al., 2016). 3D printed structures are of interest in the tissue engineering field, as they allow the manufacturing of complex and patient-tailored shapes with controlled macroporosity.

\section{Silk Foams}

Silk memory foams offer a promising and minimally invasive solution for soft tissue regeneration. These materials can be compressed prior to implantation, and then have the ability to recover their volume post-injection or implantation (Brown et al., 2017). In vivo, these materials have shown promise as soft tissue fillers, colonized by migrating cells and integrating with the surrounding native tissue (Bellas et al., 2015). These foams can be used as a drug delivery vehicles for bioactive molecules, and their degradation has been tuned using pre-loaded enzymes (Chambre et al., 2020). Likewise, these foams have been loaded with Dinutuximab, a monoclonal antibody with clinical potential for patients with high-risk neuroblastoma (Ornell et al., 2020). These silk foams induced a significant decrease in tumor growth rate in a mouse orthotopic tumor model. Overall, these materials are extremely well-suited for soft tissue regeneration and localized drug-delivery at an injury site.

\section{Microneedles}

The mechanical properties, biocompatibility, biodegradability, benign processing conditions, and stabilizing effect of silk on biological compounds has made it a important candidate for the fabrication of microneedle systems for drug delivery. The degradation rate of $\mathrm{SF}$ and the diffusion rate of the entrained molecules can be controlled by adjusting postprocessing conditions (Yin et al., 2018). The microneedles can be further combined with other materials to make composite microneedles and further tune the drug release profile. These microneedles have been prepared with insulin (Wang S. et al., 2019), antibiotics (Tsioris et al., 2012), and vaccines (Demuth et al., 2014; Boopathy et al., 2019). Products based on this technology are currently being developed and commercialized for therapeutic applications.

\section{Hard Silk Materials}

The mechanical properties of regenerated silk materials can be tuned for orthopedic applications requiring hard materials by controlling the fabrication process ( $\mathrm{Li}$ et al., 2016). Bulk regenerated silk-based materials with excellent mechanical properties were generated through a biomimetic, all-aqueous process. These materials replicated the nanoscale structure of natural silk fibers and demonstrated excellent machinability, allowing the fabrication of resorbable bone screws, intermedullary nails and fixation plates. These devices allowed functionalization with bioactive molecules like antibiotics, morphogens, or micro RNAs (James et al., 2019). Recent work developed a thermal processing method allowing the direct solid-state molding of regenerated silk nanoparticles into bulk "parts" or devices with tunable mechanical properties (Guo et al., 2020). Thus, robust materials that retain biocompatibility, degradability and machinability, without the time, cost, and stability limitations of using silk solution-derived methods represents a significant advance.

\section{Films}

Silk can be processed into thin films by air drying, methanolor water-annealing, or even electrogelation (Stinson et al., 2020). Glycerol can be added to the formulation to obtain flexible silk films (Lu et al., 2010). While silk films are promising in the field of drug delivery (Zhou et al., 2014), or for the long-term stabilization of vaccines (Stinson et al., 2020), they also have direct applications in tissue engineering. Their interesting optical transparency and thin format make them candidates for corneal tissue models. The films sustain cell adhesion and growth; they can also be physically and chemically patterned to mimic the cellular and ECM organization of the cornea (Lawrence et al., 2009). Pores can also be added in the films to enhance translamellar nutrient diffusion and cell-cell interactions. These films can be further stacked into multi-lamellar, helicoidal structures, and functionalized with RGD-peptides, allowing a biomimetic 3D corneal model (Gil et al., 2010).

\section{APPLICATIONS}

The versatility of silk materials and their tunable properties drive interest for many applications, particularly in tissue engineering (Kundu et al., 2013; Li G. et al., 2015), wearable electronics (Kim et al., 2010), and pollution control (Ling et al., 2017; Gao et al., 2018). 


\section{Silk Fibroin Biocompatibility}

Evaluating the biocompatibility of any medical device is a crucial step during its development. Biocompatibility is the fact that a biomaterial is "accepted" by the organism with minimal cytotoxicity and immunogenicity with the aim to prevent any rejection of the biomaterial. However, biocompatibility is dependent on the shape and the time of contact and use of the material. Therefore, every material should be tested in their final form to assess their compatibility. Silk materials have long been used as silk sutures; however, hypersensitivity has been shown in some cases, even it remains scarce. Silk being a foreign body material, when implanted, a mild inflammatory response is generally observed. This immunogenic response has been linked to the presence of sericin (residual or due to the use of non-degummed silk) within the material (Kundu et al., 2013). However, no immunogenicity has been found when using materials composed of a single silk protein, either fibroin or sericin (Bandyopadhyay et al., 2019). Many studies have shown the biocompatibility of alkali heat degummed silk materials, such as SF electrospun mats, films, gels, and microparticles. Interestingly, in vivo studies showed that silk induced a lower inflammatory response compared to type I collagen and PLA (Rockwood et al., 2011). Finally, the FDA has approved the use of silk for medical uses in the US (Zhang et al., 2017).

\section{Biomedical Applications}

Silk materials can match most of the challenges in the biomedical field due to their mechanical robustness, biocompatibility, and biodegradability. The various material formats obtained from silk, as described above, can be used in many different medical applications.

Silk sutures have been used in the medical field for a long time, and were patented in 1966, thus establishing the possibility to use silk in medicine. Silk sutures were first developed to overcome the mechanical problems encountered with traditional sutures. Surgical sutures require a great tensile strength to keep both ends of the wound tight together even under physiological movements such as heartbeat, stomach or intestinal peristalsis, or muscle contraction and relaxation. In addition, surgeons should be able to knot sutures. Silk was a suitable candidate fiber as it met all these requirements. Since then, silk materials have been developed for many applications in the biomedical field, such as for wound dressings, skin, bone, cartilage, ocular, vascular, neuronal, and tissue regeneration in general (Kundu et al., 2013).

\section{Wound Dressing}

After sutures, wound dressings are probably the most common application of silk materials in the biomedical field. Several studies have found that silk materials induce faster reepithelization than conventional materials in skin burn wounds. Functionalization of electrospun silk materials has been pursued, such as with epidermal growth factor (EGF) and silver sulfadiazine, improving the overall wound healing process (Gil et al., 2013). Functionalization was also be achieved using silk microparticles (Li X. et al., 2017), such as with insulin for chronic wound healing applications. Insulin was chosen because of its contribution to wound healing and its acceleration of reepithelization. The overall wound healing effect was studied in vivo in diabetic rats and the insulin-loaded SF materials resulted in increased wound closure rates compared to non-loaded SF materials and conventional gauze.

\section{Skin Equivalents}

Silk-based materials have emerged in the field of skin equivalents due to the ability to improve wound closure, as well as its biocompatibility and biodegradability properties. One model of artificial skin was produced by silk electrospinning (Sheikh et al., 2015). Three different electrospinning techniques were compared: (i) traditional electrospinning (TE), (ii) salt leaching electrospinning (SLE), and (iii) cold plate electrospinning (CPE). CPE materials provided thicker materials, as ice crystals preserved the conductivity of the deposited material, thus enhancing the deposition of polymer depth. In addition, CPEobtained materials showed increased cell infiltration and the possibility to generate an artificial skin substitute when culturing keratinocytes at the air-liquid interface. Finally, CPE can be used over curved surfaces, thus, making it easier to produce personalized skin systems.

Cells were included in a silk-based skin equivalent (Vidal et al., 2019). This complex skin equivalent included adipose tissue, endothelial cells, keratinocytes, neural cells, immune cells, and vascularization systems. The hypodermis was constructed on a silk sponge by salt leaching. Dermis and epidermis layers were shaped into a hydrogel containing complete cell culture media, silk, collagen, and fibroblasts. The two layers of materials were then combined to form a full-thickness skin equivalent. The presence of silk in the material was crucial to overcome the concerns about collagen skin equivalents, which is construct contraction over time; this is prevented by the silk due to its stable structure. In addition, the mechanical properties of silkcontaining hydrogels were closer to skin than pure collagen materials. Moreover, silk-containing materials were useful for up to 6 weeks in vitro, providing the possibility to study patientspecific immune and neuronal responses for a longer period of time.

\section{Bone Regeneration}

Bone tissue engineering materials have been described (Bhattacharjee et al., 2017) with characteristics including: mechanical properties comparable to bone, biocompatibility, bioresorption and the capacity to deliver osteoprogenitor cells and growth factors. In addition, scaffolds should be able to provide mechanical integrity until the bone is completely regenerated, as they have to support high mechanical loads and stimuli. Resorbable materials are preferred as they avoid the need for a second surgery to remove the devices or implant. Collagen is the preferred material; however, a lack of mechanical properties limits its utility, synthetic polymers are used as alternatives. An extended review on silk-based materials for bone tissue engineering has been published (Bhattacharjee et al., 2017), and highlights the potential to exploit the versatility of silk materials as cellularized scaffolds or acellular biomaterials for bone tissue engineering. For example, guided bone regeneration was successfully achieved with silk membranes (Cai et al., 
2017a). The main objective was to generate a material able to avoid connective tissue invasion into a bone defect after surgery. Invasion of the defect by soft tissue makes bone regeneration impossible, resulting in the local loss of function. In their in vivo experiments, the material performed as well as commercially available products.

\section{Vascular Tissue Engineering}

The gold standard for cardiovascular disease is autologous transplantation (autografts). However, limited donor tissue availability as well as donor site morbidity drive the need to develop new materials and tissue engineering approaches. Some synthetic materials are already used to construct vascular grafts, namely expanded polytetratfluoroethylene (ePTFE, Teflon ${ }^{\circledR}$ ) and polyethylene terephthalate (PET, Dacron $\left.{ }^{\circledR}\right)$. These materials are largely used for large diameter vessels or artery replacement. However, when replacing small diameter vessels $(<6 \mathrm{~mm})$ these materials fail when compared with autografts. Moreover, clinical complications such as aneurysms, intimal hyperplasia and thrombosis are associated with their use. Due to their characteristic mechanical properties and biocompatibility, silk materials have also been used in the field of vascular tissue engineering. Small vessel graft were developed with silk, where the diameter of the tube could be tailored and the graft was rich in $\beta$-sheet-structure to confer appropriate mechanical properties (Lovett et al., 2007). The incorporation of polyethylene oxide into the silk dispersion resulted in optimal porosity once the PEO was removed, enabling small protein transport but limiting endothelial cell migration. Vessel grafts were produced by combining two electrospun layers and an intermediate textile layer (Alessandrino et al., 2019). The mechanical properties were similar to native arteries, had biocompatibility, cell adhesion and blood hemocompatibility (no complement activation). However, further optimization is needed to reduce a foreign body response in vivo in sheep and minipigs.

\section{Nerve Regeneration}

Neural guidance is a key factor for efficient nerve regeneration. A three-layered silk electrospun material (aligned-random-aligned fibers) was generated to address this need (Belanger et al., 2018). The aligned electrospun silk material induced alignment in Schwann cells in contrast to the random growth found when cultured on glass coverslips. In vivo experiments in rats showed successful nerve regeneration after 4 months, with mechanical properties matching the tensile stress of the rat sciatic nerve (ca. 2.6 MPa). The insulating characteristics of silk materials may impair electrical potential for neural action and communication, thus composite approaches may be useful.

\section{Drug Delivery}

The controllable degradation rate of SF materials in the body enables their use as drug delivery devices. Gentamicin sulfate impregnated gelatin microspheres were embedded into silk scaffolds obtained by freeze drying (Lan et al., 2014). The material showed a reduced inflammatory response and accelerated reepithelization in vivo while exhibiting antibacterial properties. Similarly, dual drug-loaded silk materials were developed ( $\mathrm{Li}$
H. et al., 2017). Silk microspheres containing curcumin were prepared and blended into a silk dispersion with the drug doxorubicin hydrochloride (DOX-HCl). By electrospinning, nanofiber silk materials were obtained containing the hydrophilic DOX-HCl in the shell and the hydrophobic curcumin in the core. Silk hydrogels can also be used for drug delivery. Silk hydrogels were loaded with bevacizumab, an anti-vascular endothelial growth factor antagonist (Lovett et al., 2015). Bevacizumab is a therapeutic agent for the treatment of age-related macular degeneration, an eye disease characterized by the progressive loss of vision. The intravitreal injection of hydrogels in rabbits' eyes showed sustained drug release for up to 90 days.

\section{Other Applications}

Although silk is increasingly being developed in the biomedical field, interesting applications have also emerged in other areas, such as for pollution control (Ling et al., 2017; Gao et al., 2018), electronics (Kim et al., 2010), thermal insulators, and fire retardants (Maleki et al., 2018). For example, silk adsorbs many chemicals and metals, which renders it interesting for water and air pollution. With this objective, electrospinning has been used to develop silk air filters (Gao et al., 2018) that have high efficiency air filtration (up to 99.99\%) for particles with mean diameters from 0.3 to $10 \mu \mathrm{m}$, and a decreased pressure drop in comparison with state-of-the-art materials. In addition, silk filters are biodegradable and can be involved in recycling or sustainability processes.

\section{NANO-OBJECTS}

Nano-objects are objects with at least one of their three dimensions at the nanoscale (smaller than $100 \mathrm{~nm}$ ). Nanoobjects are classified into three groups: nanoplates, nanofibers, and nanoparticles (NPs). According to the IUPAC, NPs are "particles" of any shape with dimensions in the 1-100 $\mathrm{nm}$ range. These nano-objects exhibit a high surface-to-volume ratio that is particularly useful in many fields, such as in catalysis and sensing. In addition, unexpected and tunable properties appear at the nanoscale, differing from the bulk material.

NPs are rapidly coated by biomolecules, mostly proteins, when injected into biological fluids, leading to the formation of a "biomolecular corona" (Monopoli et al., 2012). The stability of NPs in solution depends on the equilibrium of attractive and repulsive forces between NPs, influenced by physicochemical conditions including the ionic strength, nature of the ions, $\mathrm{pH}$, temperature, and the presence of bio-organic compounds (e.g., steric effects). Destabilization of the NPs solution may result in aggregation and precipitation. Given these considerations (protein corona formation and stability of NPs solution) it is unlikely that NPs preserve their initial size over time in the body. Large-sized NPs can be easily eliminated from the body through conventional routes. The remaining NPs can be taken up, stored and even degraded by cells to limit bioavailability (Van de Walle et al., 2019; Balfourier et al., 2020; Plan Sangnier et al., 2020).

NPs can be synthesized by top-down or bottom-up methods. Top-down synthesis consists of breaking down the bulk material 
until the obtention of nanosized particles, such as ballmilling, laser ablation, and lithography. Bottom-up synthesis is performed by building up the nanomaterial atom by atom or molecule by molecule. Bottom-up methods are liquid synthesis and include chemical precipitation, sol-gel processes and micellar and inverse micellar synthesis, hydro/solvo-thermal methods, etc. (Su and Chang, 2017). Many different synthesis routes are actually used for different materials as a standard and consistent synthesis method for all NPs has not yet been found to our knowledge.

\section{Noble Metal Nanoparticles}

Noble metal NPs are of particular interest in materials because the reduction of material needed allows decreasing costs and lower its environmental impact. Many noble metal NPs are currently used in several applications such as catalysis, biomedicine, environment depollution or electronics.

\section{Gold NPs}

Gold NPs are probably the most well-known type of NPs since the preparation of the colloidal "ruby" gold by Michael Faraday in the 19th century. These NPs are used in many fields, from medicine (imaging, diagnostics, therapeutics) to electronics, essentially due to their unique reactivity and optical properties emerging only at the nanoscale.

Gold NPs have been used for their surface plasmon resonance (SPR) effect that results in an enhancement of the electromagnetic field in the surface of the NPs and optical extinction at the plasmon resonance frequency. SPR allows gold NPs to be used as hyperthermia agents due to their capability to absorb light at a given frequency and transforming the energy into heat (Plan Sangnier et al., 2019; Balfourier et al., 2020). Gold NPs have also been largely used in sensing systems (Zhou et al., 2015; De Crozals et al., 2016; Szekeres and Kneipp, 2019), as contrast agents for computed tomography (CT), as antibacterial agents (Cui et al., 2012), and as catalyst (Alshammari, 2019; Begum et al., 2019).

\section{Silver NPs}

Silver is known for its antibacterial action. The use of silver as an antibacterial agent had decreased with the arrival of antibiotics. However, the widespread use of these powerful molecules has led to the apparition of antibiotic-resistant bacterial strains. Silver NPs have broad spectrum activity against gram positive and gram negative bacteria (Agnihotri et al., 2014), biofilms (Guo et al., 2019), multidrug resistant bacteria (Lara et al., 2010a), fungi (Kim et al., 2009; Chudasama et al., 2011), and even some virus (Lara et al., 2010b). The antibacterial action of silver NPs is dependent on their size and shape (Choi and Hu, 2008).

Silver was initially used it its ionic form for biomedical applications, and, in particular, in surgical cloths and wound dressings (Uttayarat et al., 2012). Although silver ions can be toxic at high concentrations, great controversies exist regarding the toxicity of silver NPs, as this property depends on their size, shape, and surface functionalization. To our knowledge, no silver NP toxicity has been proven except the one resulting from the release of $\mathrm{Ag}^{+}$ions. Therefore, silver NPs are actually being widely used as antibacterial agents (Reidy et al., 2013). Additionally, they can also be used for sensing applications (Annadhasan et al., 2014), as conductive elements in electronics (Cai et al., 2017b) and in environmental remediation applications as they possessed also catalytical properties allowing the degradation of several pollutants in water (Guerra et al., 2018).

\section{Other Noble Metal NPs (Pd, Pt)}

Platinum and palladium NPs are well-known in the catalysis field. Both metals are expensive which drives the industry interests toward the reduction of metal needed to obtain the same result. When used in their nanoparticulate form their catalytic performance increases due to the higher surface-to-volume ratio.

Platinum is mainly used in hydrogenation/dehydrogenation reactions, fuel cell applications, $\mathrm{CO}$, and alcohol oxidations (Martínez-Prieto et al., 2017). On the other hand palladium NPs are used as catalyzers mainly in C-C coupling reactions (Suzuki-Miyaura, Sonogashira and Mizoroki-Heck reactions), reduction of nitroarenes, hydrogenation of alkenes and alkynes, and oxidation of primary alcohols (Saldan et al., 2015). Both metal NPs have been used as well for depollution applications (Iben Ayad et al., 2020), photothermal treatments (Samadi et al., 2018; Yang et al., 2019) and as antibacterial/antifungal agents (Dumas and Couvreur, 2015; Pedone et al., 2017).

\section{Quantum Dots}

Quantum dots (QDs) are semiconductor NPs of small size (usually smaller than $10 \mathrm{~nm}$ ). Because of their tunable fluorescent properties in a large light spectrum (from infrared to visible light), cadmium selenide (CdSe), cadmium telluride (CdTe), and cadmium sulfide (CdS) have been developed. In the biomedical field, QDs are used as biosensors, imaging probes and for diagnostics among others (Pandey and Bodas, 2020). QDs have been also used in photocatalysis applications. For example, the production of hydrogen using QD photocatalysis has been studied. This possibility is interesting for the use of hydrogen as an alternative combustible (Rao et al., 2019).

\section{Metal Oxide Nanoparticles Iron Oxide NPs}

Iron oxide NPs are of special interest because of their magnetic properties that differ from the bulk material. Similar to the LSPR effect, iron oxide particles present superparamagnetic behaviors in the nanoscale range (NPs of diameter below 20-30 nm). Because of their small size, these NPs act as single domain particles. They are magnetized in a uniform manner, with all the spins aligned in the same direction when a magnetic field is applied (Cardoso et al., 2018). Again, the magnetic properties of iron oxide NPs strongly depend on their size and shape, as well as their crystalline state (Demortière et al., 2011; Wu et al., 2016). The use of iron oxide NPs in the biomedical field is possible due to their biocompatibility and low toxicity. Because of their magnetic properties and their relaxation times, iron oxide NPs are good candidates for magnetic resonance imaging (MRI) contrast agents. Iron oxide NPs are a type T2 contrast agent resulting in a black contrast. These NPs are also used for protein, molecule or cell separation thanks to their magnetic properties 
(Cardoso et al., 2018; Cheng et al., 2019). Iron oxide NPs can be also used for hyperthermia treatments (Liang et al., 2019; Pires et al., 2019), drug delivery (Benyettou et al., 2019), tissue adhesion (Meddahi-Pellé et al., 2014) as magnetic stimulant (Santos et al., 2015), and as pollutant sorbents (Gutierrez et al., 2017).

\section{Titanium Oxide NPs}

Titanium oxide $\left(\mathrm{TiO}_{2}\right)$ is a semiconductor metal used as a white pigment in paints, plastic, papers, cosmetics, food (E171), toothpaste among many others. This white appearance is due to its high refractive index (2.48-2.89) that results in the reflection of $96 \%$ of light. In addition, the high opacity of $\mathrm{TiO}_{2} \mathrm{NPs}_{\text {places }}$ it as the most used white pigment among industry. $\mathrm{TiO}_{2}$ is also the active component of sunscreens due to its capacity to absorb UV irradiation. Smaller NPs are preferred in this case as they result in colorless and fluid products (Lan et al., 2013). $\mathrm{TiO}_{2}$ NPs are also well-known because of their photocatalytic activity. Under ultraviolet irradiation, $\mathrm{TiO}_{2}$ electrons are excited and can be part of chemical reactions in the surface of the material. This property is mainly used for water hydrolysis to produce hydrogen, pollutant degradation (in air or water) resulting in auto-cleanable surfaces and bactericidal effect due to ROS production. Because of its biocompatibility, low cost, and high photocatalytic activity, $\mathrm{TiO}_{2} \mathrm{NPs}$ are the most used photocatalyst (Haider et al., 2019), even if their reactivity in aqueous media is impacted by aggregation (Degabriel et al., 2018).

In the biomedical field, the photocatalytic activity of $\mathrm{TiO}_{2} \mathrm{NPs}$ has been used for photodynamic treatment of infections, cancers and skin defects as psoriasis (Ahmad et al., 2015). However, this application is limited due to UV irradiation-induced damage in human tissues. To avoid direct use of UV radiation, NP surface modifications can be made, resulting in a shift in light absorption enabling the use of a different light source (Ni et al., 2017; Ziental et al., 2020). $\mathrm{TiO}_{2}$ NPs have been the subject of a vast literature regarding their toxicity, sometimes polemical (Horváth et al., 2018; Suzuki et al., 2020), and their interaction with proteins impacting cell behavior (Jayaram et al., 2017; Runa et al., 2017).

\section{Other Metal Oxide NPs (Cu, Zn)}

Other metal oxide NPs have been developed and are being used in industry. This group of NPs is used in many applications including antibacterial agents, gas sensors, catalysis, and electronics (Chavali and Nikolova, 2019). Zinc and copper oxide NPs are two of the most important ones aside from titanium oxide, and widely used in catalysis and as antibacterial agents (Stankic et al., 2016). Increasing research in the biomedical field raises the applications of metal oxide NPs as anticancer agents, anti-inflammatory and radiation protection among others (Augustine and Hasan, 2020).

\section{Hydroxyapatite, Bioactive Glass, and Silica NPs}

Bioceramics, including hydroxyapatite (HAP), present low tensile strength and brittleness. This is an issue in bone tissue engineering applications, where biomechanical loads, including torsion, bending, compression, shear stress are frequently applied to the implanted scaffold. Further, their limited remodeling (Sun et al., 2009) and uncontrolled degradation in vivo can lead to changes in the extracellular environment, which can cause adverse effects including cell death (Ge et al., 2008). Polymer/hydroxyapatite nanocomposites offer a promising solution to these issues, by combining the tunable degradability of polymers like silk with the osteoconductivity of ceramic materials (Zhang et al., 2019). The composition of these composites can be tuned to present mechanical properties closer to that of native bone, while preserving biocompatibility and biosorption properties. The nanoscale features of HAP NPs are particularly advantageous because nanotopography modulates cell behaviors like adhesion, differentiation, and proliferation, by promoting greater protein interactions and therefore new bone formation (Van Der Sanden et al., 2010).

Bioactive glasses and glass-ceramics stimulate a beneficial response in vivo by bonding to the host bone tissue (Jones, 2013). Further, the controlled release of biologically active calcium and silica ions from these materials leads to the upregulation and activation of genes associated to osteoblastic differentiation, encouraging rapid bone regeneration (Jones, 2013). The controlled release of ions from the dissolution bioactive glasses can induce angiogenesis, opening up further possibilities for enhanced bone or soft tissue regeneration (Hench, 2009). Like with HAP, one of the primary limitations on the clinical use of bioactive glasses is the unpredictable behavior in complex physiological loading conditions. Incorporating them as biologically active phases into composite systems is a promising solution to overcome these challenges.

\section{Graphene Oxide}

Graphene is an interesting nanomaterial owing to its high mechanical strength and outstanding electrical conductivity among others. However, its low solubility reduces its utilization possibilities. Instead, graphene oxide (GO) is easier to synthetize and has better solubility, while matching the mechanical strength of graphene. Further, the presence of chemical groups in GO allows its functionalization and interaction with surrounding molecules (Smith et al., 2019). Because of its electronic configuration, GO nanosheets are impenetrable by many different gases and so can be used as barriers for such molecules. The same molecule exclusion principle together with the highwater permeability of GO has been used to create water filters for wastewater treatment (Thebo et al., 2018). For the same reason, $\mathrm{GO}$ is also used as coating to avoid material corrosion (Smith et al., 2019). GO conformation is easily altered when exposed to humidity, light, or heat. This property allows the development of stimuli-responsive materials. For example, the presence of humidity results in GO swelling (Chen et al., 2017).

\section{SILK-BASED BIONANOCOMPOSITES}

The promising potential of combining silk and NPs for the design of bionanocomposites with tailored properties and functions has been pursued. Nanocomposites can present new properties that are not achieved in a classical composite with the same materials. Bionanocomposites are nanocomposites containing a biological 
material such as collagen, cellulose, alginate or silk. They have been studied to develop replacement tissues, such as tendon (Yang et al., 2016), corneal stroma (Watanabe et al., 2020), bone (Raja and Yun, 2016) and dermis (Song et al., 2015).

However, these properties are only achieved if the NPs are homogeneously distributed within the resultant material. Therefore, when developing any type of nanocomposite, it is crucial to consider the NP surface chemistry, stabilization within the bulk material and homogeneous distribution. As previously explained, NP stabilization can be easily altered by changing the physicochemical conditions of their environment, such as ionic strength. Mixing NPs with other material results in a new environment so it is not surprising to observe NP aggregation and precipitation within the material. These considerations are particularly important for silk bionanocomposites as in this case silk gelation can easily occur as well due to NP addition to the solution.

Silk bionanomaterials have been generated using at least three different methods. In situ synthesis was studied using many different reducing agents (Table 1), including the ability of silk to reduce metal ions (Yu et al., 2017; Zhou et al., 2020). Figures 2B-D show silk electrospun biocomposites obtained by in situ synthesis of gold (Au NPs) and iron oxide nanoparticles (IONPs). Although this approach reduces the number of steps needed to produce the bionanocomposite, the resultant NPs can be polydisperse in size and shape. Moreover, the surface chemistry of these NPs is unknown. These issues could result in unpredictable properties and toxicity, which are highly dependent on the characteristics of the NPs. Better control of NP characteristics can be achieved by synthesis upstream and subsequently incorporating them into silk materials. Figure 2 shows an example of silver NPs embedded in silk fibers (Figures 2E-G) and sponges (Figure 2H) obtained by using the latter procedure. However, in these cases it is important to stabilize NPs in solution by controlling their surface chemistry. Therefore, many studies have been conducted to further understand the stability of NPs in the solution (Hotze et al., 2010). Nevertheless, it is shown that, once included within the bulk material, the confinement of NPs enhances their stability by decreasing particle-particle interactions (Chandran et al., 2014). In addition, in many situations, the direct incorporation of NPs into regenerated silk solution induces silk gelation. Some studies have focused on feeding the desired NPs directly to silkworms, with incorporation in the silk cocoons, however, the efficiency of incorporation is low due to the NP biodistribution in the worm (Xu et al., 2019).

\section{Antibacterial Activity}

In the textile world of silk, the incorporation of antibacterial NPs allows for improvement of luxury clothes and reduces odors. In the biomedical field, the presence of such NPs avoids, or at least delays, infections. Silver NPs are used for antibacterial applications and silk materials have been functionalized with silver NPs. UV irradiation was used to synthetize silver NPs directly in silk solutions (Jia et al., 2017), films (Zhou et al., 2019), sponges (Hu et al., 2020), fibers, textiles and electrospun mats (Calamak et al., 2015; Jia et al., 2017; Ribeiro et al.,
2017; Zhou et al., 2019; Hu et al., 2020; Raho et al., 2020). In situ synthesis of NPs in silk textiles was not uniform over the fibers, likely due to a different silver ion adsorption depending on the silk chemical groups. Silver ion release was studied for electrospun mats and was dependent on $\beta$-sheet content. Electrospun materials with low $\beta$-sheet content resulted in cytotoxic effects in mammalian cells. Light was used as a reducing agent for the in situ synthesis of silver NPs in silk (Patil et al., 2015) and a gelling agent. The antibacterial activity of the silver NPs demonstrated. However, no tests were performed for the gel nanocomposite. The topical application of this gel in animal skin wound models resulted in faster wound closure in comparison with silk, silver NPs and Carbopol gels and Soframycin gel, a commercially available product (Patil et al., 2015). A difference was observed between silk and silver NPs/silk gels, suggesting a synergistic effect of both components in wound healing.

Silver NP-loaded silk hydrogels have been also used for bone regeneration (Ribeiro et al., 2017). Silver NPs were synthesized in situ using light as a reducing agent. Antibacterial activity was found for hydrogels containing more than $0.5 \%$ silver NPs. Cytocompatibility was assessed by seeding osteoblast cells on the hydrogels, while a silver NPs concentration-dependent decrease in cell viability was observed.

In situ NP synthesis in silk materials has also been developed using caffeic acid, flavonoids, vitamin C, citrate, Rhizophora apiculata leaf extracts, Streptomyces cell extracts or honeysuckle extracts as reducing agents (Dhas et al., 2015; Meng et al., 2016; Shahid et al., 2017; Zhou and Tang, 2018a,b; Baygar et al., 2019; Gao et al., 2019). The materials acquired antibacterial activities and showed no cytotoxic effects. Interestingly, the materials synthetized using caffeic acid had UV irradiation protection, suggesting applications in sun protective materials.

Silk sponges and films containing silver NPs have been developed (Yu et al., 2012; Das and Dhar, 2014). Silk alone was able to reduce $\mathrm{Ag}^{+}$into $\mathrm{Ag}^{0}$ efficiently to form silver NPs. The reduction ability of SF, sericin and peptides has also been shown by others (Zhang et al., 2014; Yu et al., 2017; Zhou et al., 2020). All these in situ synthesis procedures resulted in NPs with uncontrolled sizes and shapes, parameters that are crucial to control in order to evaluate NP properties. In addition, no information about NP surface chemistry or the presence of remaining toxic silver ions was described. Altogether, materials obtained by this methodology may not possess the desired antibacterial properties and may also present undesired properties such as toxicity.

Mixing preformed NPs with silk has also been pursued (Gulrajani et al., 2008; Karthikeyan et al., 2011). A two-step functionalization of silk fabrics with silver NPs was reported (Gulrajani et al., 2008). The silk fabric was soaked in silver NPs solution and the effect of $\mathrm{pH}$ on NP uptake was assessed, finding greater adsorbtion in acidic media. Silk uptake of NPs was also temperature dependent, with improved adsorption at 40 vs. $80^{\circ} \mathrm{C}$.

A two-step method was developed to functionalize silk fabrics with silver NPs (Zhou and Tang, 2018a). Interestingly the resulting materials were inhibited the growth of both Escherichia 
TABLE 1 | Applications, NPs, functionalization method, and silk materials for silk-based bionanocomposites.

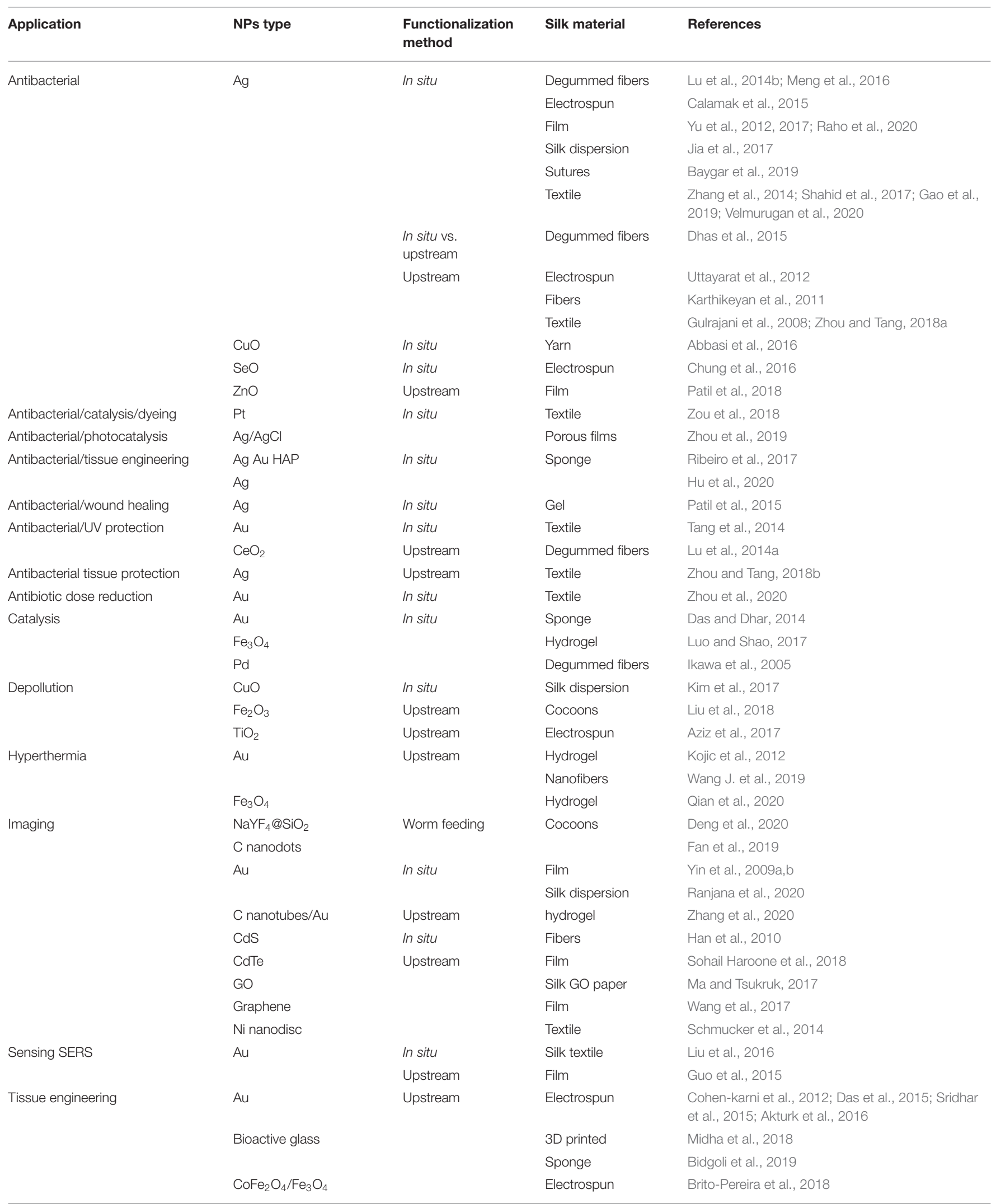


TABLE 1 | Continued

\begin{tabular}{|c|c|c|c|c|}
\hline Application & NPs type & $\begin{array}{l}\text { Functionalization } \\
\text { method }\end{array}$ & Silk material & References \\
\hline & Cu bioactive glass & & Hydrogel & Wu et al., 2019 \\
\hline & $\mathrm{Fe}_{3} \mathrm{O}_{4}$ & & Sponge & Aliramaji et al., 2017; Tanasa et al., 2020 \\
\hline & GO & & Hydrogel & Wang et al., 2020 \\
\hline & HAP & In situ & 3D printed & Huang et al., 2019 \\
\hline & & & $\begin{array}{l}\text { Compacted } \\
\text { powder }\end{array}$ & Zakharov et al., 2017 \\
\hline & & & Silk dispersion & Kong et al., 2004 \\
\hline & & Upstream & 3D printed & Sun et al., 2012 \\
\hline & & & Fibers & Heimbach et al., 2018 \\
\hline & & & Hydrogel & Ding et al., 2017 \\
\hline & & & Sponge & Kweon et al., 2011; Ye et al., 2017 \\
\hline & $\mathrm{HAP} \mathrm{TiO}_{2}$ & Upstream & Sponge & Kim et al., 2016 \\
\hline & Silica & & Film & Mieszawska et al., 2010 \\
\hline Wearable electronics & $\mathrm{Au}$ & Upstream & Film & Tao et al., 2010 \\
\hline
\end{tabular}
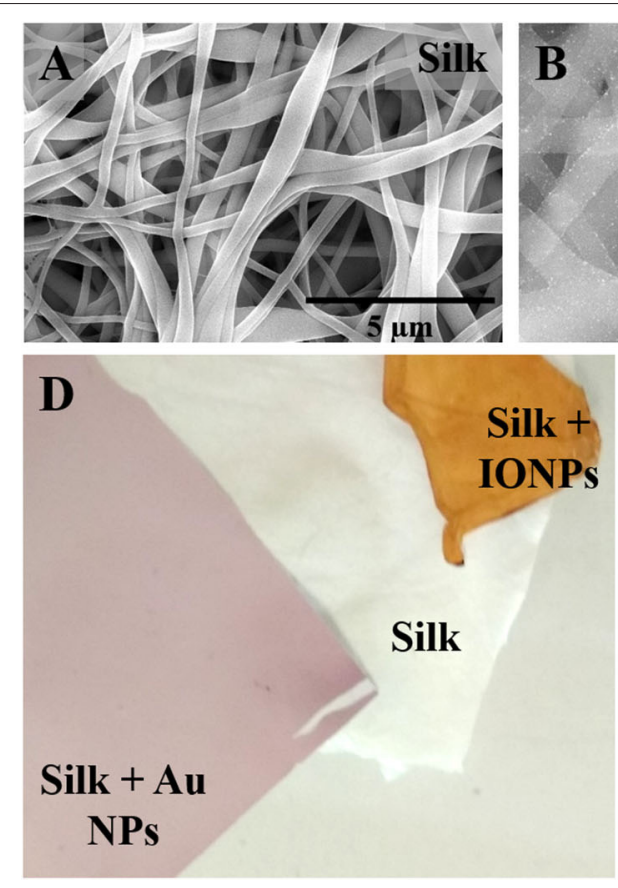
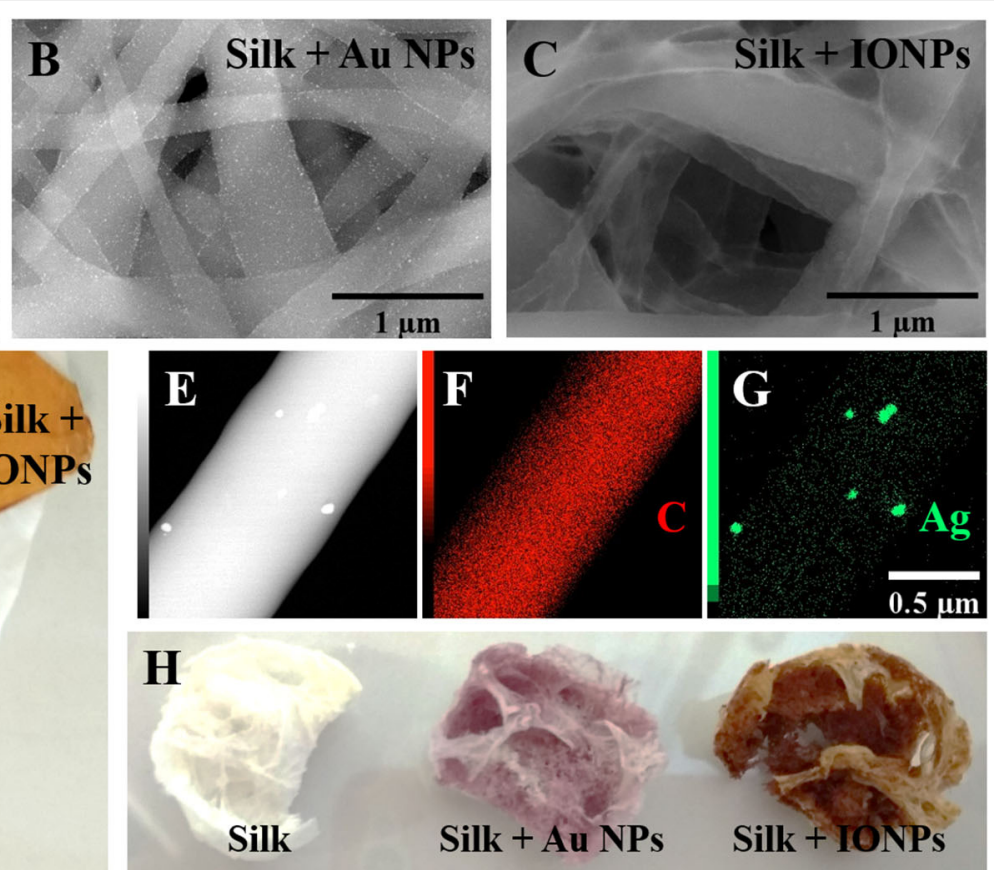
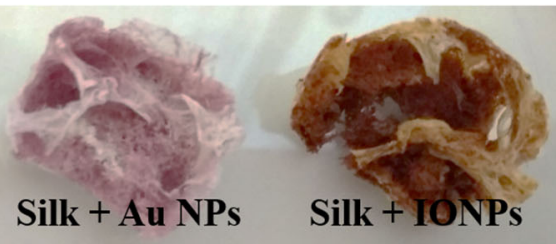

FIGURE 2 | Examples of silk bionanocomposites. Scanning Electron Microscopy view of electrospun silk fibers (A) with gold nanoparticles (Au NPs) (B), iron oxide nanoparticles (IONPs) (C) or silver nanoparticles (Ag NPs) [(E-G), STEM-EDS with elemental mapping]. Macroscopic view of electrospun scaffolds (D) and sponges (H) with gold (Au NPs) and iron oxide nanoparticles (IONPS).

coli and Staphylococcus aureus even after 30 washes, suggesting a strong bond between the silk and silver NPs.

Other studies have focused on the antibacterial activity of gold (Ribeiro et al., 2017; Zhou et al., 2020), platinum (Zou et al., 2018), copper oxide (Abbasi et al., 2016), zinc oxide (Patil et al., 2018), cerium oxide (Lu et al., 2014a), selenium oxide NPs (Chung et al., 2016) in silk materials.
The in situ synthesis of gold NPs in a HAP-containing silk hydrogel was carried out (Ribeiro et al., 2017). Once the hydrogel formed, gold NPs were synthesized by heating the solution to $60^{\circ} \mathrm{C}$. Significant antibacterial activity was observed against $S$. aureus (Multidrug sensible and resistant strains), E. coli and Pseudomonas aeruginosa, but not against Staphylococcus epidermidis. 
The in situ synthesis of gold NPs in silk fabrics was attained by heating to $85^{\circ} \mathrm{C}$ (Tang et al., 2014). The result was an antibacterial, UV irradiation blocking and thermal conducting material $\mathrm{v}$ for textile applications. However, as for the silver NPs, in situ synthesis does not allow tight control of NP size.

\section{Tissue Engineering}

Different NPs containing silk materials have been developed for tissue engineering. Gold NPs can be incorporated into the silk electrospinning solution to obtain silk nanofibers with welldispersed gold NPs by traditional (Cohen-karni et al., 2012) and wet (Akturk et al., 2016) electrospinning techniques. In both cases, the incorporation of gold NPs into electrospun silk materials resulted in improved mechanical properties. In vitro tests showed no cytotoxicity to the materials, and a good cell attachment to the scaffolds. In addition, cell attachment was enhanced by functionalizing the gold NPs with the integrin binding peptides RGD. The resultant materials were tested in vivo for wound closure (Akturk et al., 2016). No significant differences were found between silk with or without the gold NPs.

The incorporation of gold NPs into silk scaffolds has been also used to increase material conductivity. Electrical stimuli are crucial for nerve and cardiac tissues, thus, this modification impacts the regeneration process for these tissues. For example, electrospun silk containing gold NPs materials were rolled into conduits to replace sciatic nerves in vivo (Das et al., 2015). As a result, gold-containing silk materials outperformed pure silk materials in term of nerve regeneration. The presence of gold NPs in silk materials also supported better mesenchymal stem cell differentiation toward the cardiac lineage (Sridhar et al., 2015).

Most silk-based bionanocomposites developed for biomedical applications have focused on bone tissue regeneration. Because of their osteoconductive properties, silk materials containing HAP, bioactive ceramics and silica NPs have been studied. Nanocomposite scaffolds of silk and HAP are particularly interesting due to the ability of silk to "regulate" the mineralization of calcium phosphates, presumably through chemical interactions involving silk chemical groups (Kong et al., 2004; Zakharov et al., 2017). Silk/HAP scaffolds were manufactured using thermally induced phase separation (TIPS) (Wei and Ma, 2004) or lyophilization (Ye et al., 2017), to generate highly porous silk/nHAP composite scaffolds. Other materials used include silk sponges (Kweon et al., 2011), hydrogels (Ding et al., 2017), or 3D printed constructs (Huang et al., 2019).

Studies with silk/HAP materials for bone regeneration have shown promising results both in vitro and in vivo due to their biocompatibility, mechanical properties, and chemical composition similar to native bone. In a rabbit radial bone defect the formation of new bone tissue with a density similar to native bone was found using silk/chitosan/HAP biodegradable scaffolds obtained by lyophilization (Ye et al., 2017). A significantly higher rate of bone formation was also found in a rabbit parietal model after 8 weeks using silk sponges loaded with HAP (Kweon et al., 2011). Silk/HAP hydrogels have also been explored for the treatment of irregular bone defects by injection (Ding et al., 2017). In vitro, these hydrogels demonstrated good cytocompatibility and osteogenic differentiation capacity. In vivo, in a rat calvarial defect model, these hydrogels were able to support the formation of new bone tissue, suggesting promising applications for bone tissue engineering (Ding et al., 2017).

A bone replacement was developed using a silk hydrogel functionalized with hydroxyapatite NPs (nano-HAP) (Ribeiro et al., 2015). HAP is a calcium phosphate widely used in bone tissue engineering as its composition is close to the mineral phase of bone tissues. In vitro experiments showed that the nanoHAP-containing materials enhanced osteoblastic phenotype. The main challenge was to avoid nano-HAP aggregation during silk gelation. The material containing $15 \mathrm{wt} \%$ of nano-HAP showed a homogeneous dispersion in the silk hydrogel with no visible aggregation. The aggregation state of nano-HAP remains, however, the main constraint for the design of a silk-based materials with a higher nano-HAP contents.

Adequately matching the morphology of the implant and the surrounding bone is crucial for the proper integration of the implant with the surrounding bone. Recent work has focused on using or tuning the rheological properties of silk/HAPbased pastes for 3D printing applications. These approaches allow the formation of biomimetic and macroporous silk/HAP nanocomposite scaffolds. Using sodium alginate (SA) as a binder, 3D printed scaffolds with large, interconnected pores and relatively high compressive strength were generated and human bone marrow-derived mesenchymal stem cells (hMSCs) seeded on the scaffolds adhered, proliferated and differentiated toward an osteogenic lineage (Huang et al., 2019). Likewise, 3D printed scaffolds composed of a gradient of silk/hydroxyapatite (HA) were generated and supported the growth of hMSCs and human mammary microvascular endothelial cells (hMMECs) (Sun et al., 2012). These cells formed intricate networks of extracellular matrices within the 3D scaffolds with vascular-like structures following the scaffold morphology (Sun et al., 2012).

In addition to scaffold-based applications for bone regeneration, silk/HAP/polylactic acid composites were developed for the fabrication of high strength bioresorbable fixation devices for clinical applications in orthopedics (Heimbach et al., 2018). Bioactive glass NPs have been also used in bone tissue engineering using silk-based materials. For example, SF-bioactive glass composites were fabricated with controlled architecture and interconnected structure by combining indirect three-dimensional (3D) inkjet printing and freeze-drying methods. The silk/bioglass composite scaffolds possessed excellent mechanical properties and stability, and supported the attachment of hMSCs and possessed osteoinductive properties (Bidgoli et al., 2019). 3D printed silk-gelatin-bioactive glass hybrids were generated with the goal of developing patient-specific grafts for bone regeneration (Midha et al., 2018). Two different bioactive glass compositions were tested, with and without strontium, and the strontiumcontaining constructs induced osteogenic differentiation of MSCs. Further, ion release from bioactive glasses in the silkgelatin ink triggered the activation of signaling pathways for in vivo bone formation (Midha et al., 2018). Bioactive glass nanoparticles can be functionalized with different ions before incorporation into silk matrices. For example, injectable 
composite hydrogels of chitosan, silk and glycerophosphate were developed and were highly porous and could be used to administer silica, calcium and copper ions in a sustained and controlled manner (Wu et al., 2019). Further, these materials were suitable for in situ injection and underwent rapid gelation under physiological conditions of temperature and $\mathrm{pH}$. In vitro, these hydrogels supported the growth of MC3T3-E1 and human umbilical vein endothelial cells, and induced them toward osteogenesis and angiogenesis, respectively. In vivo, the copperfunctionalized hydrogels restored critical-size rat calvarial bone defects with the newly formed bone tissue vascularized with mineralized collagen deposition in 8 weeks (Wu et al., 2019).

In addition, incorporating silica NPs in silk matrices to confer osteoinductive properties, silica-functionalized silk films were prepared where hMSCs adhered, proliferated, and differentiated toward an osteogenic lineage (Mieszawska et al., 2010). The presence of silica led to upregulation of osteogenic gene expression, including bone sialoprotein and collagen type 1 . Collagen fibers and apatite nodules were observed, indicating the formation of new mineralized bone tissue (Mieszawska et al., 2010).

Other NPs have also been incorporated into silk materials for bone tissue engineering. For example $\mathrm{TiO}_{2} \mathrm{NPs}$ or GO have been used to increase the mechanical resistance of silk sponges and hydrogels (Kim et al., 2016; Wang et al., 2020). Magnetic NPs have interesting properties that can be used to apply a magnetic stimuli to cells and tissues (Aliramaji et al., 2017; Brito-Pereira et al., 2018; Tanasa et al., 2020). Recently a silk chitosan magnetite bionanocomposite scaffold was prepared by freeze casting (Aliramaji et al., 2017). They addition of magnetite NPs to the silk/chitosan scaffold did not change the porosity and no magnetite release was detected in a PBS solution after $48 \mathrm{~h}$, to support the stability of NPs in the scaffolds. The combination of magnetite NPs within the scaffolds, together with the static magnetic field applied resulted in no osteosarcoma cell cytotoxicity and increased cell attachment.

Overall, the results described above demonstrate the potential of NP incorporation in silk as a tool for material functionalization; improving mechanical properties, and also to serve as biochemical cues for the surrounding cells toward bone tissue engineering. As our understanding of mechanisms and signaling pathways progresses, the regeneration of complex tissues may benefit from combinations of NPs in silk scaffolding, including spatial patterning, to induce improved and perhaps patterned regeneration outcomes.

\section{Hyperthermia}

Hyperthermia as a therapy for the treatment of cancer uses various external energies, such as microwave, ultrasound, infrared radiations, to locally increase the body temperature and therefore destroy tumor cells. The heaters can be plasmonic or superparamagnetic NPs (Chicheł et al., 2007; Kolosnjaj-Tabi et al., 2017). Among hyperthermia modalities, phototheraphy is an interesting non-invasive therapy, in which light is used to induce local cell death. Due to the intrinsic light absorption of biological tissues, photothermal therapies can be only achieved in the near infrared region (NIR). State-of-the-art photothermal agents, namely gold nanorods and nanostars, are not efficient in the NRI II transparency window.

Silk nanofibers containing gold NPs were developed (Wang J. et al., 2019). The specific assembly of NPs results in the broader absorption of light in the NIR and a red shift of the maximum. As a result, gold NP-containing silk nanofibers reached higher temperatures than gold NPs alone under the same conditions. Therefore, the ability to pattern how and where NPs adhere to silk materials result in increased efficiency (Plan Sangnier et al., 2020).

Differently, injectable silk hydrogels containing gold NPs have also been developed for photothermal treatments of infections (Kojic et al., 2012). Silk hydrogels were obtained by vortexing silk solutions in which gold NPs were incorporated. The hydrogels were injected in the infected site and heat was produced by laser exposition. Interestingly heat was produced locally and was able to reduce bacterial populations, thus, reducing infection. The silk hydrogel assured spatial localization of the gold NPs at the injection site. Light penetration limits in biological structures can be overcome by using magnetic fields for hyperthermia treatments. In this case magnetic nanoparticles are placed in the treatment zone and heat is produced in an external magnetic field (Sohail et al., 2017). Injectable silk hydrogels have been formulated for intratumoral injection using this strategy (Qian et al., 2020). The application of a magnetic field successfully enabled deep tumor ablation while no damage was observed in the surrounding healthy tissue. Furthermore, the magnetic field can be used to direct the material to the target spot, reducing systemic distribution of the magnetic NPs.

\section{Imaging}

The possibility to follow silk implants by non-invasive imaging can be achieved by introducing fluorescent or contrast agents into the material. As an example, the introduction of iron oxide NPs into silk materials allows the use of MRI for visualization in vivo (Qian et al., 2020). NIR emitting $\mathrm{NaYF}_{4} @ \mathrm{SiO}_{2} \mathrm{NPs}_{\text {were }}$ synthetized and silk cocoons were functionalized by directly feeding silk worms with the NPs (Deng et al., 2020). The resultant silk materials were visible by NIR II imaging once implanted into mice. Similarly, silkworms were fed with fluorescent carbon nanodots resulting in fluorescent silk fibers (Fan et al., 2019). Although the materials showed no cytotoxicity, the fluorescent capacity was not evaluated in vivo. These results are encouraging for the in vivo monitoring of silk implants.

\section{Electronics and Sensing}

The transparency, flexibility, biodegradability and biocompatibility properties of silk materials have been used to develop wearable electrodes and sensors. In many cases, NPs are incorporated to support increased detection sensitivity. As in hyperthermia, gold NPs-containing silk materials have been coupled to thermoelectric chips. By doing so and incorporating the chip into an implantable device, light can be used as an energy source (Tao et al., 2010).

Silk sensors have been developed to detect ammonia (Ranjana et al., 2020) and immunoglobulin G (Sohail Haroone et al., 2018). For example, the detection of ammonia was achieved with in 
situ-synthetized gold NPs in a silk dispersion with UV-B light as reducing agent (Ranjana et al., 2020). Interestingly, the UV absorption of gold NPs decreased as the ammonia concentration increased. However, no control of the size and shape of the NPs was observed, and absorbance is dependent on these features. Silk materials have also been used to protect enzyme-mediated biosensors for the detection of hydrogen peroxide (Yin et al., 2009a), as well as methyl paraoxon, carbofuran and phoxim (Yin et al., 2009b).

Gold NPs-embedded silk films have been developed to enhance Surface-Enhanced Raman Spectroscopy (SERS) signals (Guo et al., 2015). The signal enhancement factor from the silk/gold NP films was around 150-fold. However, t light absorption by the gold NPs was influenced by the presence of the silk and red shifted by $20 \mathrm{~nm}$. This result indicated a silkinduced change in the optical properties of the gold NPs, possibly due to the different refractive indexes of silk and the aqueous solution. The results suggest a capability of these films to be used as biosensors. Similar findings based on in situ-synthetized gold NPs in silk fabrics have been reported (Liu et al., 2016).

Silk hydrogels containing carbon nanotubes have been developed to respond to mechanical stimuli (Zhang et al., 2020). The composites were able to sense pressure variations, bending and compression forces. These abilities are interesting for medical applications such as to monitor arterial pressure and intracranial pressure. Gold NPs were integrated into the system, resulting in a laser-mediated degradation due to heat production. Altogether the silk hydrogels were able to trigger a laser exposition-mediated degradation when detecting epileptic episodes (mechanical stimuli). The incorporation of drugs into the hydrogel allows for controlled therapy.

Microcircuits were printed on a silk/GO-based paper ( $\mathrm{Ma}$ and Tsukruk, 2017). The possibility to have a well-designed circuit structure allows the fine-tuning of electrode responses to external stimuli such as changes in relative humidity or proximity sensing. Silk materials were also used to prevent fluorescence quenching due to QD aggregation (Han et al., 2010). The immobilization of CdTe QDs increased fluorescence lifetime and IgG sensing capability. Silk fibers have also been used to direct the arrangement and in situ synthesis of CdS QDs for photoluminescence applications (Han et al., 2010). Surprisingly, physical and chemical nanotags for anticounterfeiting applications have also been developed where nickel nanodisc structures with or without chromophores were embedded into silk textiles by electrospinning (Schmucker et al., 2014). The unlimited combinations of structure and chromophores enabled the generation of multiple tags identifying different products.

\section{Catalysis}

Currently, nanocatalysts are used for industrial applications due to the increased surface-to-volume ratio, allowing the same catalytic activity as in bulk materials but requiring less catalyst. However, because of their nanometric dimensions, their collection for reutilization is particularly difficult. Therefore, there is an increasing interest in immobilizing nanomaterials into supports, and silk has been used for its biodegradation and biocompatible features. Catalysis activities of platinum (Zou et al., 2018), gold (Das and Dhar, 2014), palladium (Ikawa et al., 2005), and iron oxide NPs (Luo and Shao, 2017) have been studied in silk materials.

Silk sponges and films containing gold NPs were developed for catalysis using the same preparation methodology used for silk materials containing silver NPs (Das and Dhar, 2014). The reduction of 4-nitrophenol catalyzed by gold NPs containing silk materials was demonstrated. Iron oxide NPs were synthetized in situ in silk materials using silk hydrogels (Luo and Shao, 2017). A co-precipitation methodology was used to prepare the embedded NPs-embedded by dipping the hydrogel into a solution containing $\mathrm{FeCl}_{2}$ and $\mathrm{FeCl}_{3}$, and adding ammonium hydroxide to trigger NP synthesis. The magnetic and catalytic activities of magnetite were preserved in the silk materials. Such materials could be used in environmental chemistry applications and be easily separated by their magnetic properties; however, their use in biological applications is compromised by the presence of ammonium hydroxide. Interestingly, the immobilization of palladium nanoparticles into silk materials conserved its catalytic activity and also enhanced the chemoselectivity of the hydrogenation catalyzed reaction (Ikawa et al., 2005).

\section{Pollution Control}

In addition to mechanical strength, biocompatibility and biodegradability of silk, this material is also a good absorbent for aromatic dyes. Therefore, the combination of absorbent properties, dependent on $\mathrm{pH}$ and dye concentration, with catalytical activity of several NPs has been explored.

The combination of silk electrospun nanofilters with $\mathrm{TiO}_{2}$ NPs for anionic dye removal was studied (Aziz et al., 2017). Interestingly, the absorption capacities of the materials increased as the NP content increased, and better absorption was achieved at acidic $\mathrm{pH}$. Similarly, silk iron oxide NPs materials were developed for anionic dye removal (Liu et al., 2018). The photocatalytic activity of $\mathrm{CuO}_{2}$ NPs embedded in silk for dye removal has also been explored (Kim et al., 2017). These results provide insights into wastewater treatments with biodegradable materials like silk, functionalized with suitable NPs. The combination of SF with hydroxyapatite was efficient for water filtration and purification (Ling et al., 2017). The material was able to remove efficiently dyes and heavy metal ions from solution, a result not achieved with conventional nanofiltration membranes. Silk can also be mixed with silica to form insulating and fire retardant materials (Maleki et al., 2018). These materials can be obtained by a one-step acid catalyzed solgel reaction. The resulting silk/silica aerogel showed low density $\left(0.11-0.19 \mathrm{~g} / \mathrm{cm}^{3}\right)$, high surface area $\left(311-798 \mathrm{~m}^{2} / \mathrm{g}\right)$, flexibility in compression, and fire retardancy.

\section{PERSPECTIVES AND FUTURE OUTLOOKS}

The great versatility of silk bionanocomposites, due to the possibility to design different material types and embed a variety of inorganic nanomaterials, is at the origin of their outstanding tailored properties and fucntion. Therefore, a better match within the material and the specific requirements for a given 
application is possible. In the biomedical field, the development of personalized silk bionanocomposite materials becomes more and more feasible. However, many issues are still to be addressed, particularly the long-term storage and batch-to-batch differences. The fate of the materials for long-term applications deserve, indeed, further investigations, to evaluate the evolution of mechanical properties due to aging, the stability of NPs and their possible release, etc. This requires in-depth physicochemical characterizations, on the one hand, and a great number of clinical trials, on the other hand. For the emerging applications, such as pollution control, silk bionanocomposites are promising as they enable the combination of pollutant adsorption and catalysis procedures.

\section{CONCLUSIONS}

Our walkthrough of the state-of-the-art supports the versatility of silk in a range of materials and applications for these materials. Silk can be shaped into many different material formats in a tunable manner. The versatility allows for easy adaptation to each application, as well as the possibility to combine silk with different NPs for new properties.

However, silk-based bionanocomposites still have some drawbacks to overcome. Two main strategies for silk bionanocomposite preparation are used: in situ synthesis and the addition of previously synthetized NPs (upstream) to silk materials. In situ synthesis methods are promising by reducing the reaction steps to obtain the final functionalized materials, such as the successful for HAP/silk bionanocomposites obtained by controlled calcium phosphate mineralization. However, silk-based bionanocomposites often fail to control NP size and shape efficiently, which determine the function of the materials. The synthesis of NPs prior to addition to silk materials raises other questions inherent to NP synthesis, control of size, surface functionality and dispersion. Although advances have been made in NP synthesis methodologies, the synthesis of NPs needs to: (i) have control over size and shape; (ii) stabilized

\section{REFERENCES}

Abbasi, A. R., Noori, N., Azadbakht, A., and Bafarani, M. (2016). Dense coating of surface mounted $\mathrm{Cu}_{2} \mathrm{O}$ nanoparticles upon silk fibers under ultrasound irradiation with antibacterial activity. J. Iran. Chem. Soc. 13, 1273-1281. doi: $10.1007 /$ s13738-016-0841-y

Agnihotri, S., Mukherji, S., and Mukherji, S. (2014). Size-controlled silver nanoparticles synthesized over the range $5-100 \mathrm{~nm}$ using the same protocol and their antibacterial efficacy. RSC Adv. 4, 3974-3983. doi: 10.1039/C3RA44507K

Ahmad, R., Mohsin, M., Ahmad, T., and Sardar, M. (2015). Alpha amylase assisted synthesis of $\mathrm{TiO}_{2}$ nanoparticles: structural characterization and application as antibacterial agents. J. Hazard. Mater. 283, 171-177. doi: 10.1016/j.jhazmat.2014.08.073

Akturk, O., Kismet, K., Yasti, A. C., Kuru, S., Duymus, M. E., Kaya, F., et al. (2016). Wet electrospun silk fibroin/gold nanoparticle 3D matrices for wound healing applications. RSC $A d v .6,13234-13250$. doi: 10.1039/C5RA2 $4225 \mathrm{H}$

Alessandrino, A., Chiarini, A., Biagiotti, M., Dal Prà, I., Bassani, G. A., Vincoli, V., et al. (2019). Three-layered silk fibroin tubular scaffold for the repair and regeneration of small caliber blood vessels: from design to in vivo pilot tests. Front. Bioeng. Biotechnol. 7, 1-17. doi: 10.3389/fbioe.2019.00356
NPs in the surrounding media and avoiding NP aggregation or precipitation; (iii) control of surface chemistry of NPs. Finally, the addition of synthesized NPs can induce silk gelation. Overall, the bionanocomposites should have NPs of controlled size, shape and surface chemistry, and these NPs should be homogeneously distributed within the silk matrix.

Silk bionanocomposites have been largely developed for antibacterial and tissue engineering applications because of their biocompatibility and biodegradation properties. Antibacterial properties allow interesting textile conservation and wound protection from infections. Moreover, the versatility given by different silk materials and the combinations with nanocomponents are well-adapted to many applications in tissue engineering. Emerging applications of silk bionancomposites have also been described in many other fields such as catalysis, electronics, imaging and sensing devices.

In the future, different combinations of silk/NPs materials may be developed for additional applications. In addition, with the increasing concern on climate change and plastic pollution, biodegradable materials based on silk should remain in the spotlight to provide new materials for new functions in medicine, for the environment, and for a range of additional needs. Improved control of NP dimensions and homogeneity will further drive this innovation in next generation silk-based materials.

\section{AUTHOR CONTRIBUTIONS}

All authors listed have made a substantial, direct and intellectual contribution to the work, and approved it for publication.

\section{ACKNOWLEDGMENTS}

CM acknowledges the financial support of Sorbonne Universités through a Doctoral Fellowship. VF and DK acknowledge the financial support of the NIH (Grant No: P41EB027062).

Aliramaji, S., Zamanian, A., and Mozafari, M. (2017). Super-paramagnetic responsive silk fibroin/chitosan/magnetite scaffolds with tunable pore structures for bone tissue engineering applications. Mater. Sci. Eng. C 70, 736-744. doi: 10.1016/j.msec.2016.09.039

Alshammari, A. S. (2019). Heterogeneous gold catalysis: from discovery to applications. Catalysts 9:402. doi: 10.3390/catal9050402

Annadhasan, M., Muthukumarasamyvel, T., Sankar Babu, V. R., and Rajendiran, N. (2014). Green synthesized silver and gold nanoparticles for colorimetric detection of $\mathrm{Hg}^{2+}, \mathrm{Pb}^{2+}$, and $\mathrm{Mn}^{2+}$ in aqueous medium. ACS Sustain. Chem. Eng. 2, 887-896. doi: 10.1021/sc400500z

Augustine, R., and Hasan, A. (2020). Emerging applications of biocompatible phytosynthesized metal/metal oxide nanoparticles in healthcare. J. Drug Deliv. Sci. Technol. 56:101516. doi: 10.1016/j.jddst.2020.101516

Aziz, S., Sabzi, M., Fattahi, A., and Arkan, E. (2017). Electrospun silk fibroin/PAN double-layer nanofibrous membranes containing polyaniline/ $/ \mathrm{TiO}_{2}$ nanoparticles for anionic dye removal. J. Polym. Res. 24, 0-6. doi: 10.1007/s10965-017-1298-0

Balfourier, A., Luciani, N., Wang, G., Lelong, G., Ersen, O., Khelfa, A., et al. (2020). Unexpected intracellular biodegradation and recrystallization of gold nanoparticles. Proc. Natl. Acad. Sci. U.S.A. 117, 103-113. doi: $10.1073 /$ pnas. 1911734116 
Bandyopadhyay, A., Chowdhury, S. K., Dey, S., Moses, J. C., and Mandal, B. B. (2019). Silk: a promising biomaterial opening new vistas towards affordable healthcare solutions. J. Indian Inst. Sci. 99, 445-487. doi: 10.1007/s41745-019-00114-y

Bang, S., Ko, Y. G., Kim, W. Il, Cho, D., Park, W. H., and Kwon, O. H. (2017). Preventing postoperative tissue adhesion using injectable carboxymethyl cellulose-pullulan hydrogels. Int. J. Biol. Macromol. 105, 886-893. doi: 10.1016/j.ijbiomac.2017.07.103

Baygar, T., Sarac, N., Ugur, A., and Karaca, I. R. (2019). Antimicrobial characteristics and biocompatibility of the surgical sutures coated with biosynthesized silver nanoparticles. Bioorg. Chem. 86, 254-258. doi: 10.1016/j.bioorg.2018.12.034

Begum, R., Najeeb, J., Sattar, A., Naseem, K., Irfan, A., Al-Sehemi, A. G., et al. (2019). Chemical reduction of methylene blue in the presence of nanocatalysts: a critical review. Rev. Chem. Eng. 0, 749-770. doi: 10.1515/revce2018-0047

Belanger, K., Schlatter, G., Hébraud, A., Marin, F., Testelin, S., Dakpé, S., et al. (2018). A multi-layered nerve guidance conduit design adapted to facilitate surgical implantation. Heal. Sci. Reports 1:e86. doi: 10.1002/hsr2.86

Bellas, E., Lo, T. J., Fournier, E. P., Brown, J. E., Abbott, R. D., Gil, E. S., et al. (2015). Injectable silk foams for soft tissue regeneration. Adv. Healthc. Mater. 4, 452-459. doi: 10.1002/adhm.201400506

Benyettou, F., Prakasam, T., Ramdas Nair, A., Witzel, I. I., Alhashimi, M., Skorjanc, T., et al. (2019). Potent and selective in vitro and in vivo antiproliferative effects of metal-organic trefoil knots. Chem. Sci. 10, 5884-5892. doi: 10.1039/C9SC01218D

Bhattacharjee, P., Kundu, B., Naskar, D., Kim, H. W., Maiti, T. K., Bhattacharya, D., et al. (2017). Silk scaffolds in bone tissue engineering: an overview. Acta Biomater. 63, 1-17. doi: 10.1016/j.actbio.2017.09.027

Bi, B., Liu, H., Kang, W., Zhuo, R., and Jiang, X. (2019). An injectable enzymatically crosslinked tyramine-modified carboxymethyl chitin hydrogel for biomedical applications. Colloids Surfaces B Biointerfaces 175, 614-624. doi: 10.1016/j.colsurfb.2018.12.029

Bidgoli, M. R., Alemzadeh, I., Tamjid, E., Khafaji, M., and Vossoughi, M. (2019). Fabrication of hierarchically porous silk fibroin-bioactive glass composite scaffold via indirect 3D printing: effect of particle size on physico-mechanical properties and in vitro cellular behavior. Mater. Sci. Eng. C 103:109688. doi: 10.1016/j.msec.2019.04.067

Boopathy, A. V., Mandal, A., Kulp, D. W., Menis, S., Bennett, N. R., Watkins, H. C., et al. (2019). Enhancing humoral immunity via sustained-release implantable microneedle patch vaccination. Proc. Natl. Acad. Sci. U.S.A. 116, 16473-16478. doi: 10.1073/pnas.1902179116

Brito-Pereira, R., Correia, D. M., Ribeiro, C., Francesko, A., Etxebarria, I., PérezÁlvarez, L., et al. (2018). Silk fibroin-magnetic hybrid composite electrospun fibers for tissue engineering applications. Compos. Part B Eng. 141, 70-75. doi: 10.1016/j.compositesb.2017.12.046

Brown, J. E., Moreau, J. E., Berman, A. M., McSherry, H. J., Coburn, J. M., Schmidt, D. F., et al. (2017). Shape memory silk protein sponges for minimally invasive tissue regeneration. Adv. Healthc. Mater. 6:e201600762. doi: 10.1002/adhm.201600762

Cai, Y., Guo, J., Chen, C., Yao, C., Chung, S. M., Yao, J., et al. (2017a). Silk fibroin membrane used for guided bone tissue regeneration. Mater. Sci. Eng. C 70, 148-154. doi: 10.1016/j.msec.2016.08.070

Cai, Y., Piao, X., Gao, W., Zhang, Z., Nie, E., and Sun, Z. (2017b). Large-scale and facile synthesis of silver nanoparticles: via a microwave method for a conductive pen. RSC Adv. 7, 34041-34048. doi: 10.1039/C7RA05125E

Calamak, S., Aksoy, E. A., Ertas, N., Erdogdu, C., Sagiroglu, M., and Ulubayram, K. (2015). Ag/silk fibroin nanofibers: effect of fibroin morphology on $\mathrm{Ag}^{+}$release and antibacterial activity. Eur. Polym. J. 67, 99-112. doi: 10.1016/j.eurpolymj.2015.03.068

Cardoso, V. F., Francesko, A., Ribeiro, C., Bañobre-López, M., Martins, P., and Lanceros-Mendez, S. (2018). Advances in magnetic nanoparticles for biomedical applications. Adv. Healthc. Mater. 7, 1-35. doi: 10.1002/adhm.201700845

Chambre, L., Parker, R. N., Allardyce, B. J., Valente, F., Rajkhowa, R., Dilley, R. J., et al. (2020). Tunable biodegradable silk-based memory foams with controlled release of antibiotics. ACS Appl. Bio Mater. 3, 2466-2472. doi: 10.1021/acsabm.0c00186
Chandran, S., Begam, N., Padmanabhan, V., and Basu, J. K. (2014) Confinement enhances dispersion in nanoparticle-polymer blend films. Nat. Commun. 5, 1-9. doi: 10.1038/ncomms4697

Chavali, M. S., and Nikolova, M. P. (2019). Metal oxide nanoparticles and their applications in nanotechnology. SN Appl. Sci. 1, 1-30. doi: $10.1007 /$ s42452-019-0592-3

Chen, L., Weng, M., Zhou, P., Zhang, L., Huang, Z., and Zhang, W. (2017). Multi-responsive actuators based on a graphene oxide composite: intelligent robot and bioinspired applications. Nanoscale 9, 9825-9833. doi: 10.1039/C7NR01913K

Cheng, F., Zhu, C., He, W., Zhao, J., and Qu, J. (2019). PSBMA-conjugated magnetic nanoparticles for selective IgG separation. Langmuir 35, 1111-1118. doi: 10.1021/acs.langmuir.8b00878

Chicheł, A., Skowronek, J., Kubaszewska, M., and Kanikowski, M. (2007). Hyperthermia - description of a method and a review of clinical applications. Reports Pract. Oncol. Radiother. 12, 267-275. doi: 10.1016/S1507-1367(10)60065-X

Choi, O., and $\mathrm{Hu}, \mathrm{Z}$. (2008). Size dependent and reactive oxygen species related nanosilver toxicity to nitrifying bacteria. Environ. Sci. Technol. 42, 4583-4588. doi: 10.1021/es703238h

Chudasama, B., Vala, A. K., Andhariya, N., Upadhyay, R. V., and Mehta, R. V. (2011). Antifungal activity of multifunctional $\mathrm{Fe}_{3} \mathrm{O}_{4}-\mathrm{Ag}$ nanocolloids. J. Magn. Magn. Mater. 323, 1233-1237. doi: 10.1016/j.jmmm.2010.11.012

Chung, S., Ercan, B., Roy, A. K., and Webster, T. J. (2016). Addition of selenium nanoparticles to electrospun silk scaffold improves the mammalian cell activity while reducing bacterial growth. Front. Physiol. 7, 1-6. doi: $10.3389 /$ fphys.2016.00297

Cohen-karni, T., Jeong, K. J., Tsui, J. H., Reznor, G., Mustata, M., Wanunu, M., et al. (2012). Nanocomposite gold-silk nano fibers. Nano Lett. 12, 5403-5406. doi: $10.1021 / \mathrm{nl} 302810 \mathrm{c}$

Cui, Y., Zhao, Y., Tian, Y., Zhang, W., Lü, X., and Jiang, X. (2012). The molecular mechanism of action of bactericidal gold nanoparticles on Escherichia coli. Biomaterials 33, 2327-2333. doi: 10.1016/j.biomaterials.2011.11.057

Das, S., and Dhar, B. B. (2014). Green synthesis of noble metal nanoparticles using cysteine-modified silk fibroin: catalysis and antibacterial activity. RSC Adv. 4, 46285-46292. doi: 10.1039/C4RA06179A

Das, S., Sharma, M., Saharia, D., Sarma, K. K., Sarma, M. G., Borthakur, B. B., et al. (2015). In vivo studies of silk based gold nano-composite conduits for functional peripheral nerve regeneration. Biomaterials 62, 66-75. doi: 10.1016/j.biomaterials.2015.04.047

De Crozals, G., Bonnet, R., Farre, C., and Chaix, C. (2016). Nanoparticles with multiple properties for biomedical applications: a strategic guide. Nano Today 11, 435-463. doi: 10.1016/j.nantod.2016.07.002

Degabriel, T., Colaço, E., Domingos, R. F., El Kirat, K., Brouri, D., Casale, S., et al. (2018). Factors impacting the aggregation/agglomeration and photocatalytic activity of highly crystalline spheroid- and rod-shaped $\mathrm{TiO}_{2}$ nanoparticles in aqueous solutions. Phys. Chem. Chem. Phys. 20, 12898-12907. doi: 10.1039/C7CP08054A

Demortière, A., Panissod, P., Pichon, B. P., Pourroy, G., Guillon, D., Donnio, B., et al. (2011). Size-dependent properties of magnetic iron oxide nanocrystals. Nanoscale 3, 225-232. doi: 10.1039/C0NR00521E

Demuth, P. C., Min, Y., Irvine, D. J., and Hammond, P. T. (2014). Implantable silk composite microneedles for programmable vaccine release kinetics and enhanced immunogenicity in transcutaneous immunization. Adv. Healthc. Mater. 3, 47-58. doi: 10.1002/adhm.201300139

Deng, Z., Huang, J., Xue, Z., Jiang, M., Li, Y., and Zeng, S. (2020). A general strategy for designing NIR-II emissive silk for the in vivo monitoring of an implanted stent model beyond $1500 \mathrm{~nm}$. J. Mater. Chem. B 8, 4587-4592. doi: 10.1039/C9TB02685A

Dhas, S. P., Anbarasan, S., Mukherjee, A., and Chandrasekaran, N. (2015). Biobased silver nanocolloid coating on silk fibers for prevention of post-surgical wound infections. Int. J. Nanomedicine 10, 159-170. doi: 10.2147/IJN.S82211

Ding, Z., Han, H., Fan, Z., Lu, H., Sang, Y., Yao, Y., et al. (2017). Nanoscale silkhydroxyapatite hydrogels for injectable bone biomaterials. ACS Appl. Mater. Interfaces 9, 16913-16921. doi: 10.1021/acsami.7b03932

Dumas, A., and Couvreur, P. (2015). Palladium: a future key player in the nanomedical field? Chem. Sci. 6, 2153-2157. doi: 10.1039/C5SC0 0070J 
Fan, S., Zheng, X., Zhan, Q., Zhang, H., Shao, H., Wang, J., et al. (2019). Super-strong and intrinsically fluorescent silkworm silk from carbon nanodots feeding. Nano-Micro Lett. 11, 1-11. doi: 10.1007/s40820-019-0303-z

Fernández-García, L., Marí-Buyé, N., Barios, J. A., Madurga, R., Elices, M., Pérez-Rigueiro, J., et al. (2016). Safety and tolerability of silk fibroin hydrogels implanted into the mouse brain. Acta Biomater. 45, 262-275. doi: 10.1016/j.actbio.2016.09.003

Frauchiger, D. A., Tekari, A., Wöltje, M., Fortunato, G., Benneker, L. M., and Gantenbein, B. (2017). A review of the application of reinforced hydrogels and silk as biomaterials for intervertebral disc repair. Eur. Cells Mater. 34, 271-290. doi: 10.22203/eCM.v034a17

Gao, A., Chen, H., Hou, A., and Xie, K. (2019). Efficient antimicrobial silk composites using synergistic effects of violacein and silver nanoparticles. Mater. Sci. Eng. C 103:109821. doi: 10.1016/j.msec.2019.109821

Gao, X., Gou, J., Zhang, L., Duan, S., and Li, C. (2018). A silk fibroin based green nano-filter for air filtration. RSC Adv. 8, 8181-8189. doi: 10.1039/C7RA12879G

Ge, Z., Jin, Z., and Cao, T. (2008). Manufacture of degradable polymeric scaffolds for bone regeneration. Biomed. Mater. 3:022001. doi: 10.1088/1748-6041/3/2/022001

Gil, E. S., Mandal, B. B., Park, S. H., Marchant, J. K., Omenetto, F. G., and Kaplan, D. L. (2010). Helicoidal multi-lamellar features of RGDfunctionalized silk biomaterials for corneal tissue engineering. Biomaterials 31, 8953-8963. doi: 10.1016/j.biomaterials.2010.08.017

Gil, E. S., Panilaitis, B., Bellas, E., and Kaplan, D. L. (2013). Functionalized silk biomaterials for wound healing. Adv. Healthc. Mater. 2, 206-217. doi: 10.1002/adhm.201200192

Guerra, F. D., Attia, M. F., Whitehead, D. C., and Alexis, F. (2018). Nanotechnology for environmental remediation: materials and applications. Molecules 23, 1-23. doi: 10.3390/molecules23071760

Gulrajani, M. L., Gupta, D., Periyasamy, S., and Muthu, S. G. (2008). Preparation and application of silver nanoparticles on silk for imparting antimicrobial properties. J. Appl. Polym. Sci. 108, 614-623. doi: 10.1002/app.27584

Guo, C., Hall, G. N., Addison, J. B., and Yarger, J. L. (2015). Gold nanoparticledoped silk film as biocompatible SERS substrate. RSC Adv. 5, 1937-1942. doi: 10.1039/C4RA11051J

Guo, C., Li, C., Vu, H. V., Hanna, P., Lechtig, A., Qiu, Y., et al. (2020). Thermoplastic moulding of regenerated silk. Nat. Mater. 19, 102-108. doi: 10.1038/s41563-019-0560-8

Guo, J., Qin, S., Wei, Y., Liu, S., Peng, H., Li, Q., et al. (2019). Silver nanoparticles exert concentration-dependent influences on biofilm development and architecture. Cell Prolif. 52, 1-8. doi: 10.1111/cpr.12616

Gutierrez, A. M., Dziubla, T. D., and Hilt, J. Z. (2017). Recent advances on iron oxide magnetic nanoparticles as sorbents of organic pollutants in water and wastewater treatment. Rev. Environ. Health 32, 111-117. doi: 10.1515/reveh-2016-0063

Haider, A. J., Jameel, Z. N., and Al-Hussaini, I. H. M. (2019). Review on: Titanium dioxide applications. Energy Procedia 157, 17-29. doi: 10.1016/j.egypro.2018.11.159

Han, J., Su, H., Dong, Q., Zhang, D., Ma, X., and Zhang, C. (2010). Patterning and photoluminescence of CdS nanocrystallites on silk fibroin fiber. J. Nanoparticle Res. 12, 347-356. doi: 10.1007/s11051-009-9622-1

Heimbach, B., Tonyali, B., Zhang, D., and Wei, M. (2018). High performance resorbable composites for load-bearing bone fixation devices. J. Mech. Behav. Biomed. Mater. 81, 1-9. doi: 10.1016/j.jmbbm.2018.01.031

Hench, L. L. (2009). Genetic design of bioactive glass. J. Eur. Ceram. Soc. 29, 1257-1265. doi: 10.1016/j.jeurceramsoc.2008.08.002

Hoang Thi, T. T., Lee, Y., Le Thi, P., and Park, K. D. (2019). Engineered horseradish peroxidase-catalyzed hydrogels with high tissue adhesiveness for biomedical applications. J. Ind. Eng. Chem. 78, 34-52. doi: 10.1016/j.jiec.2019.05.026

Horváth, T., Papp, A., Igaz, N., Kovács, D., Kozma, G., Trenka, V., et al. (2018). Pulmonary impact of titanium dioxide nanorods: examination of nanorodexposed rat lungs and human alveolar cells. Int. J. Nanomedicine 13, 7061-7077. doi: 10.2147/IJN.S179159

Hotze, E. M., Phenrat, T., and Lowry, G. V. (2010). Nanoparticle aggregation: challenges to understanding transport and reactivity in the environment. $J$. Environ. Qual. 39, 1909-1924. doi: 10.2134/jeq2009.0462

Hou, X., Mu, L., Chen, F., and Hu, X. (2018). Emerging investigator series: design of hydrogel nanocomposites for the detection and removal of pollutants: from nanosheets, network structures, and biocompatibility to machine-learningassisted design. Environ. Sci. Nano 5, 2216-2240. doi: 10.1039/C8EN00552D

Hu, C., Wu, L., Zhou, C., Sun, H., Gao, P., Xu, X., et al. (2020). Berberine/Ag nanoparticle embedded biomimetic calcium phosphate sca ff olds for enhancing antibacterial function. Nanotechnol. Rev. 9, 568-579. doi: 10.1515/ntrev-2020-0046

Huang, T., Fan, C., Zhu, M., Zhu, Y., Zhang, W., and Li, L. (2019). 3Dprinted scaffolds of biomineralized hydroxyapatite nanocomposite on silk fibroin for improving bone regeneration. Appl. Surf. Sci. 467-468, 345-353. doi: 10.1016/j.apsusc.2018.10.166

Iben Ayad, A., Luart, D., Ould Dris, A., and Guénin, E. (2020). Kinetic analysis of 4-nitrophenol reduction by "water-soluble" palladium nanoparticles. Nanomaterials 10:1169. doi: 10.3390/nano10061169

Ikawa, T., Sajiki, H., and Hirota, K. (2005). Highly chemoselective hydrogenation method using novel finely dispersed palladium catalyst on silk-fibroin: its preparation and activity. Tetrahedron 61, 2217-2231. doi: 10.1016/j.tet.2004.11.080

James, E. N., Van Doren, E., Li, C., and Kaplan, D. L. (2019). Silk biomaterialsmediated miRNA functionalized orthopedic devices. Tissue Eng. 25, 12-23. doi: 10.1089/ten.tea.2017.0455

Jayaram, D. T., Runa, S., Kemp, M. L., and Payne, C. K. (2017). Nanoparticleinduced oxidation of corona proteins initiates an oxidative stress response in cells. Nanoscale 9, 7595-7601. doi: 10.1039/C6NR09500C

Jia, M., Chen, Z., Guo, Y., Chen, X., and Zhao, X. (2017). Efficacy of silk fibroinnano silver against staphylococcus aureus biofilms in a rabbit model of sinusitis. Int. J. Nanomedicine 12, 2933-2939. doi: 10.2147/IJN.S130160

Jones, J. R. (2013). Review of bioactive glass: from Hench to hybrids. Acta Biomater. 9, 4457-4486. doi: 10.1016/j.actbio.2012.08.023

Jose, R. R., Brown, J. E., Polido, K. E., Omenetto, F. G., and Kaplan, D. L. (2015). Polyol-silk bioink formulations as two-part room-temperature curable materials for 3D printing. ACS Biomater. Sci. Eng. 1, 780-788. doi: $10.1021 /$ acsbiomaterials.5b00160

Karageorgiou, V., and Kaplan, D. (2005). Porosity of 3D biomaterial scaffolds and osteogenesis. Biomaterials 26, 5474-5491. doi: 10.1016/j.biomaterials.2005.02.002

Karthikeyan, K., Sekar, S., Pandima Devi, M., Inbasekaran, S., Lakshminarasaiah, C. H., and Sastry, T. P. (2011). Fabrication of novel biofibers by coating silk fibroin with chitosan impregnated with silver nanoparticles. J. Mater. Sci. Mater. Med. 22, 2721-2726. doi: 10.1007/s10856-011-4462-9

Kim, D. H., Viventi, J., Amsden, J. J., Xiao, J., Vigeland, L., Kim, Y. S., et al. (2010). Dissolvable films of silk fibroin for ultrathin conformal bio-integrated electronics. Nat. Mater. 9, 1-7. doi: 10.1038/nmat2745

Kim, J., Kim, D., Joo, O., Woo, H., Min, J., Mi, B., et al. (2016). International Journal of Biological Macromolecules Osteoinductive silk fibroin/titanium dioxide/hydroxyapatite hybrid scaffold for bone tissue engineering. Int. J. Biol. Macromol. 82, 160-167. doi: 10.1016/j.ijbiomac.2015.08.001

Kim, J. W., Ki, C. S., Um, I. C., and Park, Y. H. (2017). A facile fabrication method and the boosted adsorption and photodegradation activity of $\mathrm{CuO}$ nanoparticles synthesized using a silk fibroin template. J. Ind. Eng. Chem. 56, 335-341. doi: 10.1016/j.jiec.2017.07.029

Kim, K. J., Sung, W. S., Suh, B. K., Moon, S. K., Choi, J. S., Kim, J. G., et al. (2009). Antifungal activity and mode of action of silver nano-particles on Candida albicans. Biometals 22, 235-242. doi: 10.1007/s10534-008-9159-2

Koh, L. D., Cheng, Y., Teng, C. P., Khin, Y. W., Loh, X. J., Tee, S. Y., et al. (2015). Structures, mechanical properties and applications of silk fibroin materials. Prog. Polym. Sci. 46, 86-110. doi: 10.1016/j.progpolymsci.2015. 02.001

Kojic, N., Pritchard, E. M., Tao, H., Brenckle, M. A., Mondia, J. P., Panilaitis, B., et al. (2012). Focal infection treatment using laser-mediated heating of injectable silk hydrogels with gold nanoparticles. Adv. Funct. Mater. 22, 3793-3798. doi: 10.1002/adfm.201200382

Kolosnjaj-Tabi, J., Marangon, I., Nicolas-Boluda, A., Silva, A. K. A., and Gazeau, F. (2017). Nanoparticle-based hyperthermia, a local treatment modulating the tumor extracellular matrix. Pharmacol. Res. 126, 123-137. doi: 10.1016/j.phrs.2017.07.010

Kong, X. D., Cui, F. Z., Wang, X. M., Zhang, M., and Zhang, W. (2004). Silk fibroin regulated mineralization of hydroxyapatite nanocrystals. J. Cryst. Growth 270, 197-202. doi: 10.1016/j.jcrysgro.2004.06.007 
Kundu, B., Rajkhowa, R., Kundu, S. C., and Wang, X. (2013). Silk fibroin biomaterials for tissue regenerations. Adv. Drug Deliv. Rev. 65, 457-470. doi: 10.1016/j.addr.2012.09.043

Kweon, H. Y., Lee, K. G., Chae, C. H., Balázsi, C., Min, S. K., Kim, J. Y., et al. (2011). Development of nano-hydroxyapatite graft with silk fibroin scaffold as a new bone substitute. J. Oral Maxillofac. Surg. 69, 1578-1586. doi: 10.1016/j.joms.2010.07.062

Lammel, A. S., Hu, X., Park, S. H., Kaplan, D. L., and Scheibel, T. R. (2010). Controlling silk fibroin particle features for drug delivery. Biomaterials 31, 4583-4591. doi: 10.1016/j.biomaterials.2010.02.024

Lan, Y., Li, W., Jiao, Y., Guo, R., Zhang, Y., Xue, W., et al. (2014). Therapeutic efficacy of antibiotic-loaded gelatin microsphere/silk fibroin scaffolds in infected full-thickness burns. Acta Biomater. 10, 3167-3176. doi: 10.1016/j.actbio.2014.03.029

Lan, Y., Lu, Y., and Ren, Z. (2013). Mini review on photocatalysis of titanium dioxide nanoparticles and their solar applications. Nano Energy 2, 1031-1045. doi: 10.1016/j.nanoen.2013.04.002

Lara, H. H., Ayala-Núñez, N. V., del Turrent, L. C. I., and Padilla, C. R. (2010a). Bactericidal effect of silver nanoparticles against multidrugresistant bacteria. World J. Microbiol. Biotechnol. 26, 615-621. doi: 10.1007/s11274-009-0211-3

Lara, H. H., Ayala-Nuñez, N. V., Ixtepan-Turrent, L., and Rodriguez-Padilla, C. (2010b). Mode of antiviral action of silver nanoparticles against HIV-1. J. Nanobiotechnology 8, 1-10. doi: 10.1186/1477-3155-8-1

Lawrence, B. D., Marchant, J. K., Pindrus, M. A., Omenetto, F. G., and Kaplan, D. L. (2009). Silk film biomaterials for cornea tissue engineering. Biomaterials 30, 1299-1308. doi: 10.1016/j.biomaterials.2008.11.018

Li, A. B., Kluge, J. A., Guziewicz, N. A., Omenetto, F. G., and Kaplan, D. L. (2015). Silk-based stabilization of biomacromolecules. J. Control. Release 219, 416-430. doi: 10.1016/j.jconrel.2015.09.037

Li, C., Hotz, B., Ling, S., Guo, J., Haas, D. S., Marelli, B., et al. (2016). Regenerated silk materials for functionalized silk orthopedic devices by mimicking natural processing. Biomaterials 110, 24-33. doi: 10.1016/j.biomaterials.2016.09.014

Li, G., Li, Y., Chen, G., He, J., Han, Y., Wang, X., et al. (2015). SilkBased Biomaterials in Biomedical Textiles and Fiber-Based Implants. Adv. Healthc. Mater. 4, 1134-1151. doi: 10.1002/adhm.201500002

Li, H., Zhu, J., Chen, S., Jia, L., and Ma, Y. (2017). Fabrication of aqueous-based dual drug loaded silk fibroin electrospun nanofibers embedded with curcuminloaded RSF nanospheres for drugs controlled release. RSC Adv. 7, 56550-56558. doi: 10.1039/C7RA12394A

Li, X., Liu, Y., Zhang, J., You, R., Qu, J., and Li, M. (2017). Functionalized silk fibroin dressing with topical bioactive insulin release for accelerated chronic wound healing. Mater. Sci. Eng. C 72, 394-404. doi: 10.1016/j.msec.2016. 11.085

Li, Z., Song, J., Zhang, J., Hao, K., Liu, L., Wu, B., et al. (2020). Topical application of silk fibroin-based hydrogel in preventing hypertrophic scars. Coll. Surf. B Biointerf. 186:110735. doi: 10.1016/j.colsurfb.2019.110735

Liang, B., Yu, K., Ling, Y., Kolios, M., Exner, A., Wang, Z., et al. (2019). An artificially engineered "tumor bio-magnet" for collecting blood-circulating nanoparticles and magnetic hyperthermia. Biomater. Sci. 7, 1815-1824. doi: 10.1039/C8BM01658E

Ling, S., Qin, Z., Huang, W., Cao, S., Kaplan, D. L., and Buehler, M. J. (2017). Design and function of biomimetic multilayer water purification membranes. Sci. Adv. 3, 1-12. doi: 10.1126/sciadv.1601939

Liu, H., Wang, Z., Li, H., Wang, H., and Yu, R. (2018). Controlled synthesis of silkworm cocoon-like $\alpha-\mathrm{Fe}_{2} \mathrm{O}_{3}$ and its adsorptive properties for organic dyes and Cr(VI). Mater. Res. Bull. 100, 302-307. doi: 10.1016/j.materresbull.2017.12.030

Liu, J., Zhou, J., Tang, B., Zeng, T., Li, Y., Li, J., et al. (2016). Surface enhanced Raman scattering (SERS) fabrics for trace analysis. Appl. Surf. Sci. 386, 296-302. doi: 10.1016/j.apsusc.2016.05.150

Lovett, M., Cannizzaro, C., Daheron, L., Messmer, B., VunjakNovakovic, G., and Kaplan, D. L. (2007). Silk fibroin microtubes for blood vessel engineering. Biomaterials 28, 5271-5279. doi: 10.1016/j.biomaterials.2007.08.008

Lovett, M. L., Wang, X., Yucel, T., York, L., Keirstead, M., Haggerty, L., et al. (2015). Silk hydrogels for sustained ocular delivery of anti-vascular endothelial growth factor (anti-VEGF) therapeutics. Eur. J. Pharm. Biopharm. 95, 271-278. doi: 10.1016/j.ejpb.2014.12.029

Lu, S., Wang, X., Lu, Q., Zhang, X., Kluge, J. A., Uppal, N., et al. (2010). Insoluble and flexible silk films containing glycerol. Biomacromolecules 11, 143-150. doi: 10.1021/bm900993n

Lu, Z., Mao, C., Meng, M., Liu, S., Tian, Y., Yu, L., et al. (2014a). Fabrication of $\mathrm{CeO}_{2}$ nanoparticle-modified silk for UV protection and antibacterial applications. J. Colloid Interface Sci. 435, 8-14. doi: 10.1016/j.jcis.2014.08.015

Lu, Z., Meng, M., Jiang, Y., and Xie, J. (2014b). UV-assisted in situ synthesis of silver nanoparticles on silk fibers for antibacterial applications. Colloids Surfaces A Physicochem. Eng. Asp. 447, 1-7. doi: 10.1016/j.colsurfa.2014.01.064

Luo, K.-y., and Shao, Z.-z. (2017). A novel regenerated silk fibroin-based hydrogels with magnetic and catalytic activities. Chinese J. Polym. Sci. 35, 515-523. doi: 10.1007/s10118-017-1910-0

Ma, R., and Tsukruk, V. V. (2017). Seriography-guided reduction of graphene oxide biopapers for wearable sensory electronics. Adv. Funct. Mater. 27:e201604802. doi: 10.1002/adfm.201604802

Maleki, H., and Huesing, N. (2019). Silica-silk fibroin hybrid (bio)aerogels: two-step versus one-step hybridization. J. Sol-Gel Sci. Technol. doi: 10.1007/s10971-019-04933-4

Maleki, H., Montes, S., Hayati-Roodbari, N., Putz, F., and Huesing, N. (2018). Compressible, thermally insulating, and fire retardant aerogels through selfassembling silk fibroin biopolymers inside a silica structure - an approach towards 3D printing of aerogels. ACS Appl. Mater. Interfaces 10, 22718-22730. doi: 10.1021/acsami.8b05856

Mandal, B. B., and Kundu, S. C. (2009). Cell proliferation and migration in silk fibroin 3D scaffolds. Biomaterials 30, 2956-2965. doi: 10.1016/j.biomaterials.2009.02.006

Martínez-Prieto, L. M., Cano, I., Márquez, A., Baquero, E. A., Tricard, S., Cusinato, L., et al. (2017). Zwitterionic amidinates as effective ligands for platinum nanoparticle hydrogenation catalysts. Chem. Sci. 8, 2931-2941. doi: 10.1039/C6SC05551F

Meddahi-Pellé, A., Legrand, A., Marcellan, A., Louedec, L., Letourneur, D., and Leibler, L. (2014). Organ repair, hemostasis, and in vivo bonding of medical devices by aqueous solutions of nanoparticles. Angew. Chemie Int. Ed. 53, 6369-6373. doi: 10.1002/anie.201401043

Meng, M., He, H., Xiao, J., Zhao, P., Xie, J., and Lu, Z. (2016). Controllable in situ synthesis of silver nanoparticles on multilayered film-coated silk fibers for antibacterial application. J. Colloid Interface Sci. 461, 369-375. doi: $10.1016 /$ j.jcis.2015.09.038

Midha, S., Kumar, S., Sharma, A., Kaur, K., Shi, X., Naruphontjirakul, P., et al. (2018). Silk fibroin-bioactive glass based advanced biomaterials: towards patient-specific bone grafts. Biomed. Mater. 13:055012. doi: 10.1088/1748-605X/aad2a9

Mieszawska, A. J., Fourligas, N., Georgakoudi, I., Ouhib, N. M., Belton, D. J., Perry, C. C., et al. (2010). Osteoinductive silk-silica composite biomaterials for bone regeneration. Biomaterials 31, 8902-8910. doi: 10.1016/j.biomaterials.2010.07.109

Monopoli, M. P., Åberg, C., Salvati, A., and Dawson, K. A. (2012). Biomolecular coronas provide the biological identity of nanosized materials. Nat. Nanotechnol. 7, 779-786. doi: 10.1038/nnano.2012.207

Mu, X., Wang, Y., Guo, C., Li, Y., Ling, S., Huang, W., et al. (2020). 3D printing of silk protein structures by aqueous solvent-directed molecular assembly. Macromol. Biosci. 20:1900191. doi: 10.1002/mabi.201900191

Nezhad-Mokhtari, P., Ghorbani, M., Roshangar, L., and Soleimani Rad, J. (2019). Chemical gelling of hydrogels-based biological macromolecules for tissue engineering: Photo- and enzymatic-crosslinking methods. Int. J. Biol. Macromol. 139, 760-772. doi: 10.1016/j.ijbiomac.2019.08.047

Ni, W., Li, M., Cui, J., Xing, Z., Li, Z., Wu, X., et al. (2017). 808 nm light triggered black TiO2 nanoparticles for killing of bladder cancer cells. Mater. Sci. Eng. C 81, 252-260. doi: 10.1016/j.msec.2017.08.020

Niu, C., Li, X., Wang, Y., Liu, X., Shi, J., and Wang, X. (2019). Design and performance of a poly(vinyl alcohol)/silk fibroin enzymatically crosslinked semi-interpenetrating hydrogel for a potential hydrophobic drug delivery. RSC Adv. 9, 41074-41082. doi: 10.1039/C9RA09344C

Ornell, K. J., Taylor, J. S., Zeki, J., Ikegaki, N., Shimada, H., Coburn, J. M., et al. (2020). Local delivery of dinutuximab from lyophilized silk fibroin foams for 
treatment of an orthotopic neuroblastoma model. Cancer Med. 9, 2891-2903. doi: $10.1002 /$ cam 4.2936

Pandey, S., and Bodas, D. (2020). High-quality quantum dots for multiplexed bioimaging: a critical review. Adv. Colloid Interface Sci. 278:102137. doi: 10.1016/j.cis.2020.102137

Partlow, B. P., Hanna, C. W., Rnjak-Kovacina, J., Moreau, J. E., Applegate, M. B., Burke, K. A., et al. (2014). Highly tunable elastomeric silk biomaterials. Adv. Funct. Mater. 24, 4615-4624. doi: 10.1002/adfm.201400526

Patil, P. P., Meshram, J. V., Bohara, R. A., Nanaware, S. G., and Pawar, S. H. (2018). $\mathrm{ZnO}$ nanoparticle-embedded silk fibroin-polyvinyl alcohol composite film: a potential dressing material for infected wounds. New J. Chem. 42, 14620-14629. doi: 10.1039/C8NJ01675E

Patil, S., George, T., and Mahadik, K. (2015). Green synthesized nanosilver loaded silk fibroin gel for enhanced wound healing. J. Drug Deliv. Sci. Technol. 30, 30-36. doi: 10.1016/j.jddst.2015.09.001

Pedone, D., Moglianetti, M., De Luca, E., Bardi, G., and Pompa, P. P. (2017). Platinum nanoparticles in nanobiomedicine. Chem. Soc. Rev. 46, 4951-4975. doi: 10.1039/C7CS00152E

Phillips, D. M., Drummy, L. F., Conrady, D. G., Fox, D. M., Naik, R. R., Stone, M. O., et al. (2004). Dissolution and regeneration of Bombyx mori silk fibroin using ionic liquids. J. Am. Chem. Soc. 126, 14350-14351. doi: 10.1021/ja046079f

Pires, F., Munhoz, F., Koch, L. M., Tanaka, M., Souza, M., Israelita, H., et al. (2019). Consenso Brasileiro de Nutrição em Transplante de CélulasTronco Hematopoiéticas : Idosos. Stem Cell Transplant. Elderly 17, 1-16. doi: 10.31744/einstein_journal/2019AE4340

Plan Sangnier, A., Aufaure, R., Cheong, S., Motte, L., Palpant, B., Tilley, R. D., et al. (2019). Raspberry-like small multicore gold nanostructures for efficient photothermal conversion in the first and second near-infrared windows. Chem. Commun. 55, 4055-4058. doi: 10.1039/C8CC09476D

Plan Sangnier, A., Van de Walle, A., Aufaure, R., Fradet, M., Motte, L., Guénin, E., et al. (2020). Endosomal confinement of gold nanospheres, nanorods, and nanoraspberries governs their photothermal identity and is beneficial for cancer cell therapy. Adv. Biosyst. 4:1900284. doi: 10.1002/adbi.201900284

Poza, P., Pérez-Rigueiro, J., Elices, M., and Lorca, J. (2002). Fractographic analysis of silkworm and spider silk. Eng. Fract. Mech. 69, 1035-1048. doi: 10.1016/S0013-7944(01)00120-5

Qian, K.-Y., Song, Y., Yan, X., Dong, L., Xue, J., Xu, Y., et al. (2020). Injectable ferrimagnetic silk fibroin hydrogel for magnetic hyperthermia ablation of deep tumor. Biomaterials 259:120299. doi: 10.1016/j.biomaterials.2020.120299

Qian, L., and Zhang, H. (2011). Controlled freezing and freeze drying: a versatile route for porous and micro-/nano-structured materials. J. Chem. Technol. Biotechnol. 86, 172-184. doi: 10.1002/jctb.2495

Raho, R., Nguyen, N. Y., Zhang, N., Jiang, W., Sannino, A., Liu, H., et al. (2020). Photo-assisted green synthesis of silver doped silk fibroin/carboxymethyl cellulose nanocomposite hydrogels for biomedical applications. Mater. Sci. Eng. C 107:110219. doi: 10.1016/j.msec.2019.1 10219

Raja, N., and Yun, H. S. (2016). A simultaneous 3D printing process for the fabrication of bioceramic and cell-laden hydrogel core/shell scaffolds with potential application in bone tissue regeneration. J. Mater. Chem. B 4, 4707-4716. doi: 10.1039/C6TB00849F

Ranjana, R., Parushuram, N., Harisha, K. S., Asha, S., and Sangappa, Y. (2020). Silk fibroin a bio-template for synthesis of different shaped gold nanoparticles: characterization and ammonia detection application. Mater. Today Proc. 27, 434-439. doi: 10.1016/j.matpr.2019.11.259

Rao, V. N., Reddy, N. L., Kumari, M. M., Cheralathan, K. K., Ravi, P., Sathish, M., et al. (2019). Sustainable hydrogen production for the greener environment by quantum dots-based efficient photocatalysts: a review. J. Environ. Manage. 248:109246. doi: 10.1016/j.jenvman.2019.07.017

Reidy, B., Haase, A., Luch, A., Dawson, K. A., and Lynch, I. (2013). Mechanisms of silver nanoparticle release, transformation and toxicity: a critical review of current knowledge and recommendations for future studies and applications. Materials 6, 2295-2350. doi: 10.3390/ma6062295

Ribeiro, M., De Moraes, M. A., Beppu, M. M., Garcia, M. P., Fernandes, M. H., Monteiro, F. J., et al. (2015). Development of silk fibroin/nanohydroxyapatite composite hydrogels for bone tissue engineering. Eur. Polym. J. 67, 66-77. doi: 10.1016/j.eurpolymj.2015.03.056
Ribeiro, M., Feraz, M. P., Monteiro, F. J., Fernandes, M. H., Beppu, M. M., Mantione, D., et al. (2017). Antibacterial silk fibroin/nanohydroxyapatite hydrogels with silver and gold nanoparticles for bone regeneration. Nanomed. Nanotechnol. Biol. Med. 13, 231-239. doi: 10.1016/j.nano.2016.08.026

Rockwood, D. N., Preda, R. C., Yücel, T., Wang, X., Lovett, M. L., and Kaplan, D. L. (2011). Materials fabrication from Bombyx mori silk fibroin. Nat. Protoc. 6, 1612-1631. doi: 10.1038/nprot.2011.379

Rodriguez, M. J., Dixon, T. A., Cohen, E., Huang, W., Omenetto, F. G., and Kaplan, D. L. (2018). 3D freeform printing of silk fibroin. Acta Biomater. 71, 379-387. doi: 10.1016/j.actbio.2018.02.035

Runa, S., Lakadamyali, M., Kemp, M. L., and Payne, C. K. (2017). $\mathrm{TiO}_{2}$ nanoparticle-induced oxidation of the plasma membrane: importance of the protein corona. J. Phys. Chem. B 121, 8619-8625. doi: 10.1021/acs.jpcb.7b04208

Saldan, I., Semenyuk, Y., Marchuk, I., and Reshetnyak, O. (2015). Chemical synthesis and application of palladium nanoparticles. J. Mater. Sci. 50, 2337-2354. doi: 10.1007/s10853-014-8802-2

Samadi, A., Klingberg, H., Jauffred, L., Kjær, A., Bendix, P. M., and Oddershede, L. B. (2018). Platinum nanoparticles: a non-toxic, effective and thermally stable alternative plasmonic material for cancer therapy and bioengineering. Nanoscale 10, 9097-9107. doi: 10.1039/C8NR02275E

Santos, L. J., Reis, R. L., and Gomes, M. E. (2015). Harnessing magnetic-mechano actuation in regenerative medicine and tissue engineering. Trends Biotechnol. 33, 471-479. doi: 10.1016/j.tibtech.2015.06.006

Schmucker, A. L., Dickerson, M. B., Rycenga, M., Mangelson, B. F., Brown, K. A., Naik, R. R., et al. (2014). Combined chemical and physical encoding with silk fibroin-embedded nanostructures. Small 10, 1485-1489. doi: 10.1002/smll.201302923

Shahid, M., Cheng, X. W., Tang, R. C., and Chen, G. (2017). Silk functionalization by caffeic acid assisted in-situ generation of silver nanoparticles. Dye. Pigment. 137, 277-283. doi: 10.1016/j.dyepig.2016.10.009

Sheikh, F. A., Ju, H. W., Lee, J. M., Moon, B. M., Park, H. J., Lee, O. J., et al. (2015). 3D electrospun silk fibroin nanofibers for fabrication of artificial skin. Nanomed. Nanotechnol. Biol. Med. 11, 681-691. doi: 10.1016/j.nano.2014.11.007

Smith, A. T., LaChance, A. M., Zeng, S., Liu, B., and Sun, L. (2019). Synthesis, properties, and applications of graphene oxide/reduced graphene oxide and their nanocomposites. Nano Mater. Sci. 1, 31-47. doi: 10.1016/j.nanoms.2019.02.004

Sohail Haroone, M., Li, L., Ahmad, A., Huang, Y., Ma, R., Zhang, P., et al. (2018). Luminous composite ultrathin films of CdTe quantum dots/silk fibroin co-assembled with layered doubled hydroxide: enhanced photoluminescence and biosensor application. J. Mater. 4, 165-171. doi: 10.1016/j.jmat.2018. 05.002

Sohail, A., Ahmad, Z., Bég, O. A., Arshad, S., and Sherin, L. (2017). Revue sur le traitement par hyperthermie médiée par nanoparticules. Bull. Cancer 104, 452-461. doi: 10.1016/j.bulcan.2017.02.003

Sommer, M. R., Schaffner, M., Carnelli, D., and Studart, A. R. (2016). 3D Printing of hierarchical silk fibroin structures. ACS Appl. Mater. Interfaces 8, 34677-34685. doi: 10.1021/acsami.6b11440

Song, J., Zhang, P., Cheng, L., Liao, Y., Xu, B., Bao, R., et al. (2015). Nano-silver in situ hybridized collagen scaffolds for regeneration of infected full-thickness burn skin. J. Mater. Chem. B 3, 4231-4241. doi: 10.1039/C5TB00205B

Song, W., Muthana, M., Mukherjee, J., Falconer, R. J., Biggs, C. A., and Zhao, X. (2017). Magnetic-silk core-shell nanoparticles as potential carriers for targeted delivery of curcumin into human breast cancer cells. ACS Biomater. Sci. Eng. 3, 1027-1038. doi: 10.1021/acsbiomaterials.7b00153

Sridhar, S., Venugopal, J. R., Sridhar, R., and Ramakrishna, S. (2015). Cardiogenic differentiation of mesenchymal stem cells with gold nanoparticle loaded functionalized nanofibers. Coll. Surf. B Biointerf. 134, 346-354. doi: 10.1016/j.colsurfb.2015.07.019

Stankic, S., Suman, S., Haque, F., and Vidic, J. (2016). Pure and multi metal oxide nanoparticles: synthesis, antibacterial and cytotoxic properties. $J$. Nanobiotechnol. 14, 1-20. doi: 10.1186/s12951-016-0225-6

Stinson, J. A., Palmer, C. R., Miller, D. P., Li, A. B., Lightner, K., Jost, H., et al. (2020). Thin silk fibroin films as a dried format for temperature stabilization of inactivated polio vaccine. Vaccine 38, 1652-1660. doi: 10.1016/j.vaccine.2019.12.062 
Su, S. S., and Chang, I. (2017). "Review of production routes of nanomaterials," in Commercialization of Nanotechnologies-A Case Study Approach, eds D. Brabazon, E. Pellicer, F. Zivic, J. Sort, M. Dolors Baró, N. Grujovic, et al. (Cham: Springer International Publishing), 15-29.

Sun, J., Shen, Q. Y., and Lu, J. X. (2009). Comparative study of microstructural remodification to porous $\beta$-TCP and HA in rabbits. Chinese Sci. Bull. 54, 2962-2967. doi: 10.1007/s11434-009-0332-y

Sun, L., Parker, S. T., Syoji, D., Wang, X., Lewis, J. A., and Kaplan, D. L. (2012). Direct-write assembly of 3D silk/hydroxyapatite scaffolds for bone co-cultures. Adv. Healthc. Mater. 1, 729-735. doi: 10.1002/adhm.201200057

Suzuki, T., Miura, N., Hojo, R., Yanagiba, Y., Suda, M., Hasegawa, T., et al. (2020). Genotoxicity assessment of titanium dioxide nanoparticle accumulation of 90 days in the liver of gpt delta transgenic mice. Genes Environ. 42:7. doi: 10.1186/s41021-020-00151-5

Szekeres, G. P., and Kneipp, J. (2019). SERS probing of proteins in gold nanoparticle agglomerates. Front. Chem. 7, 1-10. doi: $10.3389 /$ fchem.2019.00030

Tanasa, E., Zaharia, C., Hudita, A., Radu, I. C., Costache, M., and Galateanu, B. (2020). Impact of the magnetic field on 3T3-E1 preosteoblasts inside SMART silk fibroin-based scaffolds decorated with magnetic nanoparticles. Mater. Sci. Eng. C 110, 1-13. doi: 10.1016/j.msec.2020.110714

Tang, B., Sun, L., Kaur, J., Yu, Y., and Wang, X. (2014). In-situ synthesis of gold nanoparticles for multifunctionalization of silk fabrics. Dye. Pigment. 103, 183-190. doi: 10.1016/j.dyepig.2013.12.008

Tao, H., Siebert, S. M., Brenckle, M. A., Averitt, R. D., Cronin-Golomb, M., Kaplan, D. L., et al. (2010). Gold nanoparticle-doped biocompatible silk films as a path to implantable thermo-electrically wireless powering devices. Appl. Phys. Lett. 97:123702. doi: 10.1063/1.3486157

Thebo, K. H., Qian, X., Zhang, Q., Chen, L., Cheng, H. M., and Ren, W. (2018). Highly stable graphene-oxide-based membranes with superior permeability. Nat. Commun. 9, 1-8. doi: 10.1038/s41467-018-03919-0

Tsioris, K., Raja, W. K., Pritchard, E. M., Panilaitis, B., Kaplan, D. L., and Omenetto, F. G. (2012). Fabrication of silk microneedles for controlled-release drug delivery. Adv. Funct. Mater. 22, 330-335. doi: 10.1002/adfm.201102012

Uttayarat, P., Jetawattana, S., Suwanmala, P., Eamsiri, J., Tangthong, T., and Pongpat, S. (2012). Antimicrobial electrospun silk fibroin mats with silver nanoparticles for wound dressing application. Fibers Polym. 13, 999-1006. doi: 10.1007/s12221-012-0999-6

Van de Walle, A., Sangnier, A. P., Abou-Hassan, A., Curcio, A., Hémadi, M., Menguy, N., et al. (2019). Biosynthesis of magnetic nanoparticles from nanodegradation products revealed in human stem cells. Proc. Natl. Acad. Sci. U.S.A. 116, 4044-4053. doi: 10.1073/pnas.1816792116

Van Der Sanden, B., Dhobb, M., Berger, F., and Wion, D. (2010). Optimizing stem cell culture. J. Cell. Biochem. 111, 801-807. doi: 10.1002/jcb.22847

van Loo, B., Salehi, S. S., Henke, S., Shamloo, A., Kamperman, T., Karperien, M., et al. (2020). Enzymatic outside-in crosslinking enables single-step microcapsule production for high-throughput 3D cell microaggregate formation. Mater. Today Bio. 6:100047. doi: 10.1016/j.mtbio.2020.100047

Velmurugan, P., Shim, J., Kim, H. W., Lim, J. M., Kim, S. A., Seo, Y. S., et al. (2020). Bio-functionalization of cotton, silk, and leather using different in-situ silver nanoparticle synthesis modules, and their antibacterial properties. Res. Chem. Intermed. 46, 999-1015. doi: $10.1007 /$ s11164-016-2481-3

Vepari, C., and Kaplan, D. L. (2007). Silk as a biomaterial. Prog. Polym. Sci. 32, 991-1007. doi: 10.1016/j.progpolymsci.2007.05.013

Vidal, S. E. L., Tamamoto, K. A., Nguyen, H., Abbott, R. D., Cairns, D. M., and Kaplan, D. L. (2019). 3D biomaterial matrix to support long term, full thickness, immuno-competent human skin equivalents with nervous system components. Biomaterials 198, 194-203. doi: 10.1016/j.biomaterials.2018.04.044

Wang, F., Jyothirmayee Aravind, S. S., Wu, H., Forys, J., Venkataraman, V., Ramanujachary, K., et al. (2017). Tunable green graphene-silk biomaterials: mechanism of protein-based nanocomposites. Mater. Sci. Eng. C 79, 728-739. doi: 10.1016/j.msec.2017.05.120

Wang, J., Zhang, Y., Jin, N., Mao, C., and Yang, M. (2019). Protein-induced gold nanoparticle assembly for improving the photothermal effect in cancer therapy. ACS Appl. Mater. Interfaces 11, 11136-11143. doi: 10.1021/acsami.8b21488

Wang, L., Lu, R., Hou, J., Nan, X., Xia, Y., Guo, Y., et al. (2020). Application of injectable silk fibroin/graphene oxide hydrogel combined with bone marrow mesenchymal stem cells in bone tissue engineering. Coll. Surf. A Physicochem. Eng. Asp. 604:125318. doi: 10.1016/j.colsurfa.2020.125318

Wang, S., Zhu, M., Zhao, L., Kuang, D., Kundu, S. C., and Lu, S. (2019). Insulinloaded silk fibroin microneedles as sustained release system. ACS Biomater. Sci. Eng. 5, 1887-1894. doi: 10.1021/acsbiomaterials.9b00229

Watanabe, K., Miwa, E., Asai, F., Seki, T., Urayama, K., Nakatani, T., et al. (2020). Highly transparent and tough filler composite elastomer inspired by the cornea. ACS Mater. Lett. 2, 325-330. doi: 10.1021/acsmaterialslett.9b00520

Wei, G., and Ma, P. X. (2004). Structure and properties of nanohydroxyapatite/polymer composite scaffolds for bone tissue engineering. Biomaterials 25, 4749-4757. doi: 10.1016/j.biomaterials.2003.12.005

Wu, J., Zheng, K., Huang, X., Liu, J., Liu, H., Boccaccini, A. R., et al. (2019). Thermally triggered injectable chitosan/silk fibroin/bioactive glass nanoparticle hydrogels for in-situ bone formation in rat calvarial bone defects. Acta Biomater. 91, 60-71. doi: 10.1016/j.actbio.2019.04.023

Wu, W., Jiang, C. Z., and Roy, V. A. L. (2016). Designed synthesis and surface engineering strategies of magnetic iron oxide nanoparticles for biomedical applications. Nanoscale 8, 19421-19474. doi: 10.1039/C6NR07542H

Xiong, R., Grant, A. M., Ma, R., Zhang, S., and Tsukruk, V. V. (2018). Naturally-derived biopolymer nanocomposites: interfacial design, properties and emerging applications. Mater. Sci. Eng. R Reports 125, 1-41. doi: 10.1016/j.mser.2018.01.002

Xu, Z., Shi, L., Yang, M., and Zhu, L. (2019). Preparation and biomedical applications of silk fibroin-nanoparticles composites with enhanced properties - a review. Mater. Sci. Eng. C 95, 302-311. doi: 10.1016/j.msec.2018.11.010

Yang, G., Lin, H., Rothrauff, B. B., Yu, S., and Tuan, R. S. (2016). Multilayered polycaprolactone/gelatin fiber-hydrogel composite for tendon tissue engineering. Acta Biomater. 35, 68-76. doi: 10.1016/j.actbio.2016.03.004

Yang, Y., Chen, M., Wu, Y., Wang, P., Zhao, Y., Zhu, W., et al. (2019). Ultrasound assisted one-step synthesis of Au@Pt dendritic nanoparticles with enhanced NIR absorption for photothermal cancer therapy. RSC Adv. 9, 28541-28547. doi: 10.1039/C9RA04286E

Ye, P., Yu, B., Deng, J., She, R. F., and Huang, W. L. (2017). Application of silk fibroin/chitosan/nano-hydroxyapatite composite scaffold in the repair of rabbit radial bone defect. Exp. Ther. Med. 14, 5547-5553. doi: 10.3892/etm.2017.5231

Yin, H., Ai, S., Shi, W., and Zhu, L. (2009a). A novel hydrogen peroxide biosensor based on horseradish peroxidase immobilized on gold nanoparticles-silk fibroin modified glassy carbon electrode and direct electrochemistry of horseradish peroxidase. Sens. Actuat. B Chem. 137, 747-753. doi: 10.1016/j.snb.2008.12.046

Yin, H., Ai, S., Xu, J., Shi, W., and Zhu, L. (2009b). Amperometric biosensor based on immobilized acetylcholinesterase on gold nanoparticles and silk fibroin modified platinum electrode for detection of methyl paraoxon, carbofuran and phoxim. J. Electroanal. Chem. 637, 21-27. doi: 10.1016/j.jelechem.2009. 09.025

Yin, Z., Kuang, D., Wang, S., Zheng, Z., Yadavalli, V. K., and Lu, S. (2018). Swellable silk fibroin microneedles for transdermal drug delivery. Int. J. Biol. Macromol. 106, 48-56. doi: 10.1016/j.ijbiomac.2017.07.178

Yu, K., Lu, F., Li, Q., Chen, H., Lu, B., Liu, J., et al. (2017). In situ assembly of $\mathrm{Ag}$ nanoparticles (AgNPs) on porous silkworm cocoon-based would film: enhanced antimicrobial and wound healing activity. Sci. Rep. 7, 1-13. doi: 10.1038/s41598-017-02270-6

Yu, W., Kuzuya, T., Hirai, S., Tamada, Y., Sawada, K., and Iwasa, T. (2012). Preparation of Ag nanoparticle dispersed silk fibroin compact. Appl. Surf. Sci. 262, 212-217. doi: 10.1016/j.apsusc.2012.05.084

Yukseloglu, S. M., Sokmen, N., and Canoglu, S. (2015). Biomaterial applications of silk fibroin electrospun nanofibres. Microelectron. Eng. 146, 43-47. doi: 10.1016/j.mee.2015.04.008

Zakharov, N. A., Demina, L. I., Aliev, A. D., Kiselev, M. R., Matveev, V. V., Orlov, M. A., et al. (2017). Synthesis and properties of calcium hydroxyapatite/silk fibroin organomineral composites. Inorg. Mater. 53, 333-342. doi: 10.1134/S0020168517030128

Zhang, G., Liu, Y., Gao, X., and Chen, Y. (2014). Synthesis of silver nanoparticles and antibacterial property of silk fabrics treated by silver nanoparticles. Nanoscale Res. Lett. 9, 1-8. doi: 10.1186/1556-276X-9-216

Zhang, L., Liu, X., Li, G., Wang, P., and Yang, Y. (2019). Tailoring degradation rates of silk fibroin scaffolds for tissue engineering. J. Biomed. Mater. Res. Part A 107, 104-113. doi: 10.1002/jbm.a.36537 
Zhang, S., Zhou, Z., Zhong, J., Shi, Z., Mao, Y., and Tao, T. H. (2020). Bodyintegrated, enzyme-triggered degradable, silk-based mechanical sensors for customized health/fitness monitoring and in situ treatment. Adv. Sci. 7, 1-10. doi: 10.1002/advs.202070071

Zhang, W., Chen, L., Chen, J., Wang, L., Gui, X., Ran, J., et al. (2017). Silk fibroin biomaterial shows safe and effective wound healing in animal models and a randomized controlled clinical trial. Adv. Healthc. Mater. 6, 1-16. doi: 10.1002/adhm.201700121

Zheng, Z., Wu, J., Liu, M., Wang, H., Li, C., Rodriguez, M. J., et al. (2018). 3D Bioprinting of self-standing silk-based bioink. Adv. Healthc. Mater. 7, 1-12. doi: 10.1002/adhm.201701026

Zhou, H., Wang, X., Wang, T., Zeng, J., Yuan, Z., Jian, J., et al. (2019). In situ decoration of Ag@AgCl nanoparticles on polyurethane/silk fibroin composite porous films for photocatalytic and antibacterial applications. Eur. Polym. J. 118, 153-162. doi: 10.1016/j.eurpolymj.2019.05.058

Zhou, J., Zhang, B., Shi, L., Zhong, J., Zhu, J., Yan, J., et al. (2014). Regenerated silk fibroin films with controllable nanostructure size and secondary structure for drug delivery. ACS Appl. Mater. Interfaces 6, 21813-21821. doi: 10.1021/am502278b

Zhou, L., Yu, K., Lu, F., Lan, G., Dai, F., Shang, S., et al. (2020). Minimizing antibiotic dosage through in situ formation of gold nanoparticles across antibacterial wound dressings: a facile approach using silk fabric as the base substrate. J. Clean. Prod. 243:118604. doi: 10.1016/j.jclepro.2019.118604

Zhou, W., Gao, X., Liu, D., and Chen, X. (2015). Gold nanoparticles for in vitro diagnostics. Chem. Rev. 115, 10575-10636. doi: 10.1021/acs.chemrev.5b00100

Key articles in our opinion are presented in bold text to help the reader find them within the reference section.
Zhou, Y., and Tang, R. C. (2018a). Facile and eco-friendly fabrication of AgNPs coated silk for antibacterial and antioxidant textiles using honeysuckle extract. J. Photochem. Photobiol. B Biol. 178, 463-471. doi: 10.1016/j.jphotobiol.2017. 12.003

Zhou, Y., and Tang, R. C. (2018b). Facile and eco-friendly fabrication of colored and bioactive silk materials using silver nanoparticles synthesized by two flavonoids. Polymers 10:404. doi: 10.3390/polym100 40404

Ziental, D., Czarczynska-Goslinska, B., Mlynarczyk, D. T., Glowacka-Sobotta, A., Stanisz, B., Goslinski, T., et al. (2020). Titanium dioxide nanoparticles: prospects and applications in medicine. Nanomaterials 10:387. doi: 10.3390/nano100 20387

Zou, F., Zhou, J., Zhang, J., Li, J., Tang, B., Chen, W., et al. (2018). Functionalization of silk with in-situ synthesized platinum nanoparticles. Materials 11, 1-13. doi: $10.3390 / \mathrm{ma1} 1101929$

Conflict of Interest: The authors declare that the research was conducted in the absence of any commercial or financial relationships that could be construed as a potential conflict of interest.

Copyright (c) 2020 Belda Marín, Fitzpatrick, Kaplan, Landoulsi, Guénin and Egles. This is an open-access article distributed under the terms of the Creative Commons Attribution License (CC BY). The use, distribution or reproduction in other forums is permitted, provided the original author(s) and the copyright owner(s) are credited and that the original publication in this journal is cited, in accordance with accepted academic practice. No use, distribution or reproduction is permitted which does not comply with these terms. 